\title{
Las salas de cine en Madrid. De los primeros cinematógrafos a la demanda por «salvar» los cines históricos de la ciudad
}

\section{Cinemas in Madrid. From the first filmmakers to the demand to "save" the city's historic cinemas}

\author{
Alejandro García Ferrero ${ }^{1}$
}

\section{INTRODUCCIÓN}

En la actualidad el ocio ha adquirido un papel dominante en nuestras formas de vida y su presencia se manifiesta en ámbitos de la experiencia anteriormente muy alejados de sus dinámicas. En el mundo del trabajo, por ejemplo, los cambios de la organización de las empresas dentro de los programas de lo que se denomina «responsabilidad social» han fomentado una mayor articulación del ocio con la producción. Así, se organizan actividades lúdicas y eventos informales entre los trabajadores que tienen como fin reforzar la integración, fomentar el buen talante, y con ello, contribuir a mejorar la competitividad. Por su parte, las nuevas TIC s han permitido la renovación y la expansión de nuevas formas de ocio en los hogares, pero también el aprovechamiento de sus recursos de entretenimiento y de diversión para apoyar objetivos educativos a través de los «serious games» y el «aprendizaje divertido». Del mismo modo, la sanidad y la gestión pública de los asuntos sociales han articulado las dinámicas del ocio para avanzar en la curación de enfermedades y en la prevención de males sociales, lo que ha permitido renovar experiencias anteriores basadas en las terapias del descanso y del entrete-

\footnotetext{
${ }^{1}$ UNED, departamento de Geografía, becario predoctoral. alejandro.garcia@bec.uned.es
} 
nimiento saludable. En definitiva, las prácticas actuales del ocio han superado los marcos tradicionales en los que se desarrollaron en tiempos anteriores integrándose con actividades y facetas de la vida cada vez más heterogéneas (Cuenca, 2000).

Esta evolución se ha visto favorecida por diferentes fenómenos de cambio cultural e ideológico que han introducido nuevas consideraciones sobre el valor de la experiencia de ocio para mantener una vida saludable y fomentar el desarrollo social y económico (Luis Gómez, 1988; WRLA, 1994). Así mismo, la mayor disponibilidad de tiempo libre y el aumento medio del poder adquisitivo, han facilitado el acceso generalizado de la población a los productos y servicios de recreación y con ello a fomentar la innovación y la renovación de las formas de entretenimiento. En este contexto, el ocio doméstico ha conocido un importante proceso de crecimiento por la extensión generalizada de la televisión, de los reproductores audiovisuales y de otros productos de la electrónica de consumo en los hogares, hechos que se han visto apoyados por el imparable proceso de individualización que afecta a los modos de vida y de perdida generalizada de las relaciones de proximidad (Álvarez Monzonillo, 2004). Por su parte, la consolidación del turismo como actividad practicada por millones de personas en todo el mundo (Organización Mundial del Turismo, 2012) ha fomentado la aparición de modalidades de consumo alternativas a los formatos convencionales, una ampliación generalizada de los destinos turísticos y un reforzamiento de las estrategias de los sectores público y privado para continuar aprovechando sus dinámicas ${ }^{2}$. Así mismo la extensión de la educación y la mayor disponibilidad de información, entre otros factores, han diversificado el consumo de la población en torno a las producciones de la industria cultural, favoreciendo con ello la renovación de la oferta y cambiando el grado de popularidad que tuvieron algunas de sus producciones en el pasado (Álvarez Monzonillo, 1993).

Todo ello ha contribuido a reforzar la funcionalidad y el significado del ocio en la actualidad por su influencia en los planos de la experiencia personal y colectiva, en la economía y en la gestión de los asuntos públicos a diferentes escalas. Así mismo, la evolución reciente del ocio ha tenido importantes efectos en el territorio por los cambios que han afectado a las instalaciones y los entornos en los que se desarrollan sus actividades. En este sentido, aunque las

\footnotetext{
${ }^{2}$ Como «utilizar las toallas durante más de un día [...] contratar a un guía local o comprar productos locales», Taleb Rifai, Secretario General de la OMT (Organización Mundial del Turismo, 2012).
} 
dinámicas de la recreación afectan y han afectado a espacios diversos, las ciudades constituyen escenarios relevantes para estudiar estas repercusiones, por su doble condición de centros de innovación en torno a nuevas prácticas y costumbres sociales -entre ellas las de ocio- y de áreas de concentración de la actividad y de la población (Barrado, 2013). Así mismo, los paisajes urbanos y los bienes patrimoniales conservados en las ciudades permiten registrar la evolución de los modos de vida de sus poblaciones, lo que facilita la comparación de las situaciones del presente con las que tuvieron lugar en el pasado (Zárate, 2012).

El estudio que se presenta en este trabajo analiza algunas de las transformaciones más relevantes que han ocasionado en el paisaje de la ciudad de Madrid los cambios que han afectado a una de sus formas de ocio más populares, la frecuentación de las salas de cine. La evolución de esta diversión en la ciudad ha estado condicionada en las últimas décadas por la caída generalizada de la afluencia a las salas de exhibición y por los cambios que han introducido en su actividad la generalización del formato multisala, su articulación con los centros comerciales y la aplicación de nuevas tecnologías para la exhibición de películas. Todo ello se enmarca en el contexto de renovación que ha afectado a los hábitos de consumo de ocio entre la población madrileña en el cambio de siglo y se ha traducido en importantes modificaciones en la imagen y la fisionomía del espacio de exhibición cinematográfico en la ciudad. Así mismo, los cierres continuados de salas como consecuencia del declive de la afluencia han desatado las protestas de particulares y de agentes de la sociedad civil por los efectos dañinos que está teniendo para garantizar la conservación de estructuras cinematográficas que forman parte del patrimonio y del paisaje en diferentes zonas de la ciudad.

Para abordar todas estas cuestiones el trabajo se ha organizado en dos partes que analizan desde una doble perspectiva: diacrónica y actual, los procesos de cambio que han introducido en diferentes escenarios urbanos la evolución histórica y reciente del sector de la exhibición cinematográfica. Las fuentes utilizadas para tratar este proceso proceden de trabajos muy variados desarrollados sobre la evolución de este sector en España y en la ciudad hasta los años setenta y de una abundante documentación estadística para los tiempos más recientes. Todo ello nos ha permitido la elaboración de una serie de mapas significativos con la ayuda de un programa de cartografía temática (ArcGIS 10.1, aplicación ArcMap). Así mismo, la información utilizada se completa con noticias de prensa y diferentes documentos técnicos sobre la evolución del cine como producto cultural y de ocio para ocupar el tiempo libre. 
EL CINE CONTRIBUYE A TRANSFORMAR LOS PAISAJES DE OCIO MADRILEÑOS

\section{Ocios tradicionales y nuevos en la ciudad en el tránsito del siglo XIX al xx}

En los primeros años del siglo xx, los hábitos de consumo de ocio entre los madrileños experimentaron una transformación importante como consecuencia de la influencia de diferentes factores de naturaleza social, económica y cultural. Los toros, las verbenas, los circos y otras formas tradicionales de entretenimiento se renovaron por los cambios que afectaron a su demanda y por el impulso a la innovación que supuso la continuada emergencia de nuevas y variadas alternativas para el entretenimiento en la ciudad. La práctica del deporte se fue extendiendo entre los escolares y los jóvenes bajo el impulso de los centros educativos extranjeros y de la Institución Libre de Enseñanza que existían en la ciudad, al tiempo que la aparición de los primeros clubes e instalaciones estables permitieron la celebración de espectáculos y de competiciones, favorecido todo por movimientos higienistas y el Krausismo que ensalzaban el contacto con la naturaleza.

Las prácticas deportivas y su consumo como espectáculo de masas fueron alentados por la prensa y la publicidad pero también, y de manera decisiva, por las mejoras en los medios de transporte intraurbanos que facilitaron la movilidad hacia los lugares de celebración de los encuentros (Báez y Pérez de Tudela, 2012). Y en determinados casos hubo un estrecho maridaje entre deporte, transporte y urbanización, pensemos lo que supuso la inauguración del Metro madrileño en 1919, el papel urbanístico jugado por la propia Sociedad Metropolitana Madrileña en las inmediaciones de Cuatro Caminos con la Colonia Metropolitana y la inauguración el 13 de mayo de 1923 del Estadio de Futbol Metropolitano para el equipo Atlético de Madrid, fundado a su vez en 1903.

Del mismo modo, la expansión urbana, con una importante inmigración hacia la capital, las reformas de las calles, la renovación de la actividad comercial y las mejoras del alumbrado público, primero de gas y luego eléctrico, favorecieron los entretenimientos fuera del hogar y posibilitaron el desarrollo de una vida nocturna más activa (Quirós, 2009), coincidiendo con el auge que experimentaban los espectáculos culturales y la renovación del sector hostelero, representado desde el punto de vista más emblemático y de impacto paisajístico por la construcción del hotel Ritz en 1908 y el Palace en 1912, magníficas muestras de la arquitectura modernista. Simultáneamente, los teatros de la villa vivieron por entonces un momento de gran esplendor por la popularidad de la zarzuela y el abaratamiento medio de los precios, mientras 
que la actividad de los numerosos cafés de la ciudad se completó con la de las moderas barras americanas y los restaurantes automáticos que se abrieron a lo largo de las primeras décadas del siglo xx. Así mismo la llegada de nuevos ritmos musicales -el jazz, el tango o el charleston- y la continuidad de la aficiones a la canción popular fomentaron la construcción y adecuación de locales en el centro y en los bordes de la ciudad para el desarrollo de sus repertorios (Báez y Pérez de Tudela, 2012).

En este contexto, tuvo lugar en 1895 la primera representación cinematográfica, en un salón habilitado en los bajos del Hotel Rusia, en la Carrera de San Jerónimo. Al igual que sucedió en otras ciudades europeas y americanas, el cine estuvo vinculado en sus primeros tiempos a las formas de ocio y de entreteniendo de la clases altas que valoraron el nuevo invento como un hito en la evolución de la técnica y de la ciencia. Este hecho y el miedo a la competencia por parte de los empresarios del sector de los espectáculos, fomentaron que las primeras exhibiciones del cine se integraran con otras alternativas para el entretenimiento de las elites, como la actividad de los casinos, de los salones y de los teatros. En Madrid, el teatro Romea, en la calle Carretas, fue el primero en alternar este espectáculo con las piezas teatrales a través del cinematógrafo Pathè, y poco más tarde, lo hicieron el de la Zarzuela y el Apolo, en las calles Jovellanos y Alcalá, respectivamente, dotando a este espectáculo de una posición de centralidad en Madrid durante sus primeros años de andadura (Crespo, 1974a; González, 2007). Con todo, la continuidad del cine como negocio en aquellos momentos tuvo un éxito limitado por el hastío y el desinterés que suscitaron entre el público las reiteradas temáticas de sus representaciones. Se trataba fundamentalmente de un cine testimonial basado en la industria, los transportes, la vida en la ciudad, etc. en suma, en acontecimientos del momento plasmados en documentales de corta duración como La llegada de un tren o La demolición de un muro, que llegaron desde Francia a la primera representación del Hotel Rusia ${ }^{3}$, o las que se elaboraron en los años posteriores en diferentes escenarios madrileños ${ }^{4}$.

En estas condiciones la incapacidad del cine para competir con las realizaciones del teatro, provocó un paulatino declinar de su presencia entre las formas de ocio de la burguesía y un desplazamiento de su actividad hacia las diversiones de la clases populares, hecho que contribuyó a extender su pre-

\footnotetext{
${ }^{3}$ Hermanos Lumiere, 1895 y 1896 (Crespo, 1974a).

${ }^{4}$ Como Riña en el café, de Fructuoso Gelabert (1897) o Salida de las alumnas del Colegio de San Luis de los Franceses y Maniobras de la artillería en Vicálvaro, finales del siglo xix y posiblemente de Alexandre Promio (Báez y Pérez de Tudela, 2012).
} 
sencia en la ciudad a través de barracas para la exhibición y como atracción de feria en las verbenas. Así, a finales del siglo XIX Madrid ya contaba con varios barracones instalados en diferentes lugares del centro -calles de Alcalá, Pez, Ancha de San Bernardo-, en el barrio de Embajadores -calle Encomienda, Ave María y Atocha- y en el Paseo del Prado, donde el cinematógrafo de Estanislao Bravo estuvo presente en las verbenas de San Juan y de San Pedro durante estos años (González, 2007).

FIGURA 1

LOCALIZACIÓN DE LOS CINES MADRILEÑOS EN 1907

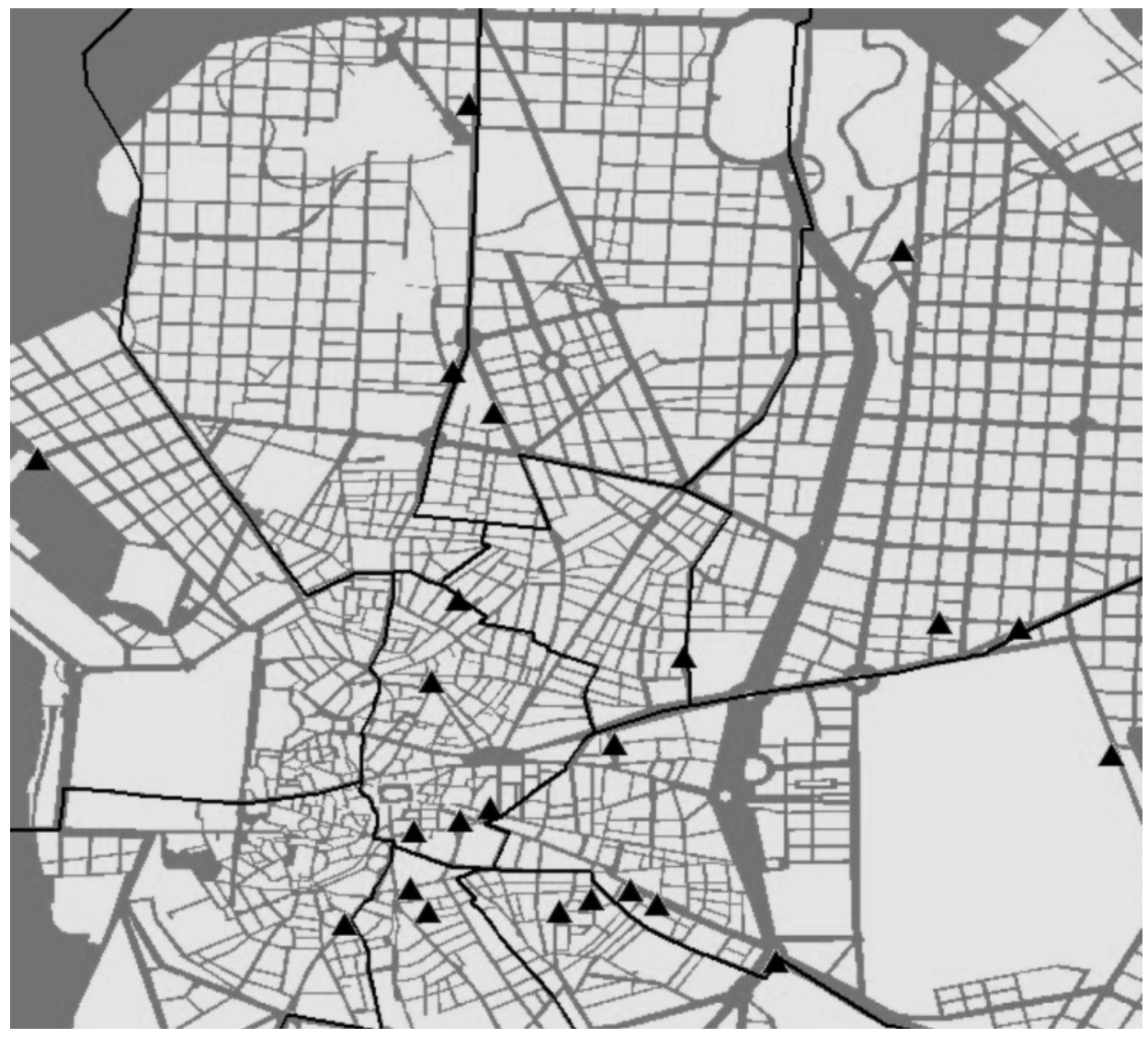

Fuente: Crespo (1974b) sobre mapa de HISDI-MAD.

Estudios Geográficos, Vol. LXXVII, 280, pp. 115-153, enero-junio 2016

ISSN: 0014-1496, eISSN: 1988-8546, doi: 10.3989/estgeogr.201605 
Aunque de manera aún muy incipiente estos locales contribuyeron a modelar la fisionomía de sus espacios de ubicación, a afianzar el consumo de cine entre la población y a extender la práctica de acercarse al centro y a sus inmediaciones para disfrutar de esta diversión (Báez y Pérez de Tudela, 2012). En los años posteriores, el desarrollo del cine argumental, y con ello la recuperación paulatina de la afluencia, permitió ampliar la presencia del cine en nuevos escenarios urbanos. En 1907 ya había 23 locales que reproducían la distribución espacial en la ciudad de los orígenes del cine: en pleno centro y en pequeñas áreas de borde urbano pero bien comunicadas, conforme al modelo de dispersión señalado a raíz de su primera crisis. Entre estas últimas, el mayor número de locales se concentraba al norte del barrio de Embajadores, en el entorno de la Glorieta de Bilbao, en el barrio de Arguelles y en el tramo de la calle de Alcalá correspondiente al barrio de Salamanca, en suma, en áreas de la ciudad urbanísticamente consolidadas, muy pobladas y bien comunicadas con el centro por lo que ofrecían ventajas para mantener una afluencia continuada a las salas (Crespo, 1974a) (figuras 1).

\section{La consolidación del cine como espectáculo de masas a partir de los años 1920}

A partir de la primera década del siglo xx, la industria del cine conoció un crecimiento generalizado a nivel mundial. Estados Unidos se convirtió en el primer productor mundial de películas y los avances del cine documental se consolidaron a partir de la aplicación del sonido a los filmes y de la renovación general de sus temáticas. Todo ello permitió superar las crisis anteriores y extender su consumo hacia sectores cada vez más amplios de la población, lo que se manifestó en la expansión de sus locales y en la mejora generalizada de los locales dedicados a su exhibición. Entre los primeros años 1920 y los anteriores a la Guerra Civil, los locales de cine en Madrid aumentaron de 27 (1921) a 61 (1935), el aforo crecerá hasta llegar a las 35.000 localidades en 1929 y los diferentes espacios ocupados por esta actividad experimentaron una profunda renovación morfológica por la reforma operada en sus locales y la construcción de otros nuevos bajo los estilos arquitectónicos del momento (figura 2). Así mismo, la progresión del negocio de la exhibición supuso la consolidación de Madrid como principal productor y distribuidor de películas de España, lo que favoreció la instalación de estudios cinematográficos en esta ciudad y la mayor presencia de los escenarios de la villa en las películas que se rodaron en estos años (Crespo, 1974a; Sánchez Fernández, 2013; López Martín, 2009; Báez y Pérez de Tudela, 2012). 
FIGURA 2

LOCALES DE CINE POR DISTRITOS ENTRE 1907 Y 1945

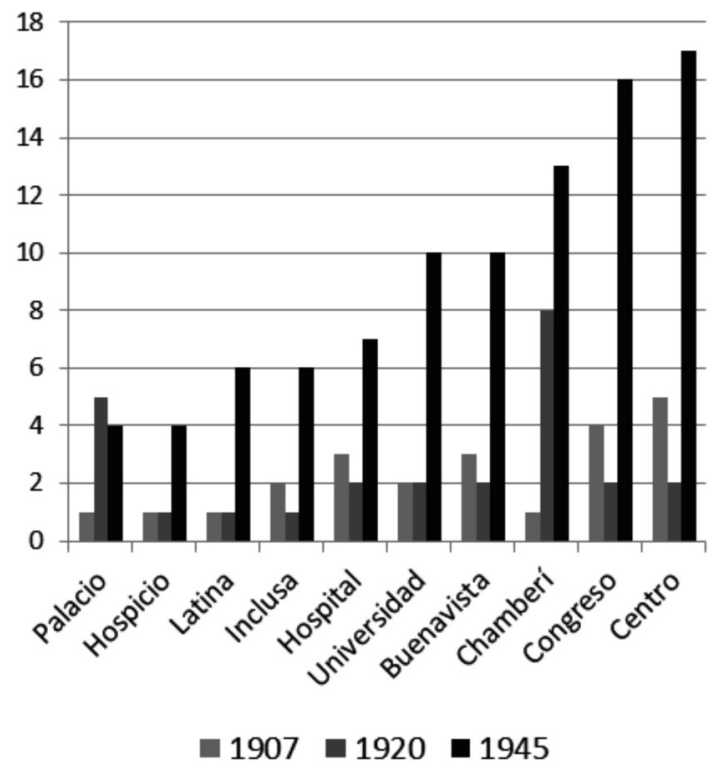

Fuente: Crespo (1974b).

Por otro lado, el crecimiento del espacio de exhibición madrileño se integró con las actuaciones de renovación y cambio urbano que afectaron a la ciudad durante estos años, hechos que contribuyeron a hacer de los cines un elemento clave para la conformación de diferentes espacios. En el centro, el proceso de construcción de la Gran Vía transformó por completo la fisionomía de esta área de la ciudad con una gran avenida comercial franqueada por altos y modernos edificios de vanguardia que conocieron desde el primer momento una rápida proliferación de cines en sus bajos comerciales y en locales exclusivos para la exhibición de películas. El proceso de ocupación de la vía por esta actividad fue prácticamente paralelo al del trazado de la Gran Vía, sobre todo a partir de su segundo tramo, el comprendido entre la Red de San Luis y la plaza del Callao, y poco después en el tercero, entre esta última plaza y la plaza de España. Antes de 1935 ya se habían abierto los principales locales de esta vía: el cine Callao (1927) (figura 3), el Palacio de la Música (1928), el Palacio de la Prensa (1928), el Avenida (1928), el Rialto (1930), el Azul (1930), el Actualidades (1931), el Coliseum (1933) y el Capitol (1933). En todos los casos, se trataba de locales de alto nivel, pro- 
yectados por renombrados arquitectos conforme a las últimas innovaciones en materiales y bajo los estilos característicos del momento, modernismo y eclecticismo (Bosque, 2000-2001), lo que justifica su interés patrimonial por la singularidad de su arquitectura. Todo ello contribuyó a hacer de la Gran Vía un espacio referencial para el sector de la exhibición de películas en la ciudad de Madrid, sobre todo hasta finales del siglo xx, situación que se reforzó con el protagonismo que tuvieron todos estos locales en la proyección de las películas de estreno. Entre 1940 y 1944, por ejemplo, siete de los cines que funcionaban entre los números 32/35 y 54/41 de la Gran Vía -menos 400 metros lineales de la avenida-, estrenaron algo más del $80 \%$ de las películas que llegaron a la ciudad 5 .

\section{FIGURA 3}

\section{EL CINE CALLAO DE 1926, UNA MUESTRA DEL ECLECTICISMO ARQUITECTÓNICO EN EL PAISAJE MADRILEÑO}

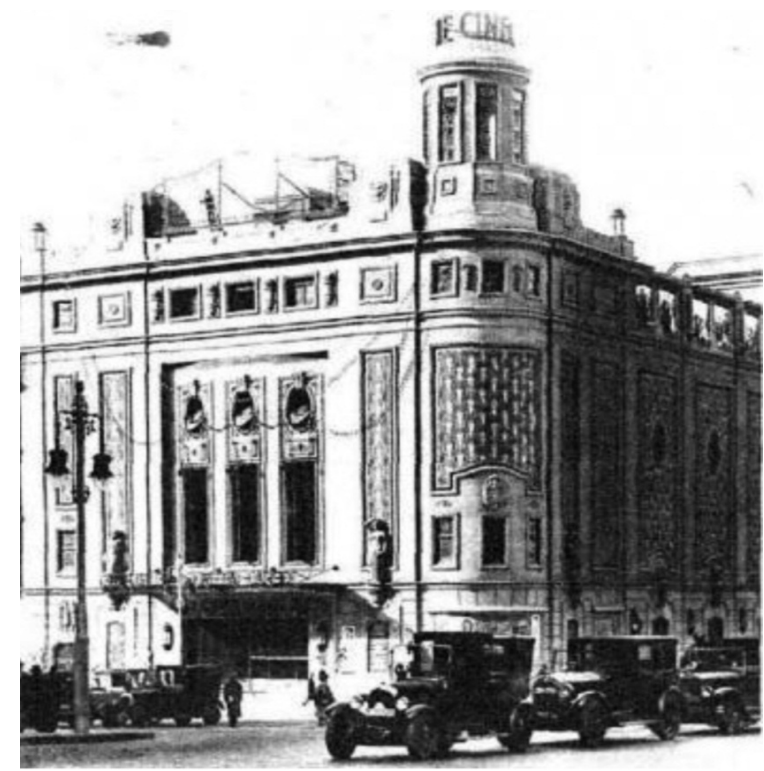

Fuente: Zapata (1928).

${ }^{5}$ Los siete locales y el porcentaje de películas de estreno con relación al total de la ciudad fueron: el Palacio de la Música (14\%), el Cine Callao (13.4\%), el Imperial (12.9\%), el Rialto (10.4\%), el Avenida (10.2\%), el Capitol (9.9\%) y el Palacio de la Prensa (9.4\%) (López García, $1945)$ 
En otros espacios del centro histórico, la renovación y la construcción de modernos locales de cine resultaron igualmente destacadas. En la calle de Santa Isabel se construyó el cine Doré (1912), en la de Atocha el Monumental (1922) y el San Carlos (1929), en la calle de Embajadores el Teatro-Cine Pavón (1924) y en Doctor Cortezo, el Fígaro (1932). En el entorno de la Plaza de Canalejas y el comienzo de la calle Alcalá, se levantaron el Salón de Madrid $(1907)^{6}$ y el Calatravas; y frente al Teatro Real, en la Plaza de Opera, el Real Cinema, que contó para su inauguración el 15 de mayo de 1920 con la presencia de la familia real (Sánchez Fernández, 2013).

De este modo, el espacio cinematográfico del centro se fue completando al tiempo que en las zonas próximas y en las periferias, la mayor consolidación de los tejidos urbanos y el crecimiento de la población favorecieron su ampliación hacia nuevas zonas de la ciudad, contando en todo caso con el éxito de masas, especialmente entre las clases populares, de la imagen en movimiento y del bajo coste de un espectáculo que ofrecía información, aventura e historias de la vida, siempre bajo las explicaciones y comentarios de un narrador y la música de una pequeña orquesta o un simple pianista, hasta finales de los años 1920 en que empieza el cine sonoro.

En Chamberí, una de las zonas más populares de la ciudad, con elevada presencia de inmigrantes, con la calle de Bravo Murillo como una de las vías de salida de Madrid camino de Francia y buena comunicación con el centro de la ciudad al inaugurarse en 1919 la primera línea del Metro, Puerta del SolCuatro Caminos, los cines proliferaron a partir de la década de los 1930, en el entorno de la Glorieta de Bilbao (Proyecciones, 1932; Luchana, 1946) y otros más dispersos por el distrito, como el Royaltí (1913) de la calle Génova, el Barceló (1931) y el cine Espronceda (1944).

Al norte de Chamberí, las reformas urbanas del Paseo de Reina Victoria y la Glorieta de Cuatro Caminos favorecieron la construcción del cine Europa (1928), del Metropolitano (1930) y el Tetuán (1930), siempre con el eje de Bravo Murillo como referencia por las razones antes señaladas.

Por su parte, el barrio de Salamanca también se llenó de nuevos locales, en las calles Goya y Alcalá, respectivamente, el Goya, 1923, y el Tívoli, 1930,... y en otros lugares, el Salamanca, 1935, y el Victoria, 1940. Simultáneamente, conforme crecía la periferia madrileña en los años 1930 y sobre todo en la posguerra, década de 1940, los locales de cine aumentaron, casi siempre en las vías principales y de salida de la ciudad, en las vías por donde discurrían las lí-

\footnotetext{
${ }^{6}$ Más tarde renombrado como Cine Cedaceros y Cine Bogart.
} 
neas de tranvía al modo de los «streets cars» características de las ciudades de la época y del modelo de ciudad dominante (Zárate, 2012). El cine se afirmaba como forma evasión de una sociedad en crisis y en profunda transformación y de comunicación con el mundo exterior a través de las películas que llegaba de fuera y de los noticiarios demográficos (el NO.DO.). De estos años son: en Ventas, el cine Becerra (1930), en el Puente de Vallecas, el cine Frutos (1934), en el Paseo de las Delicias-Legazpi, los cines Legazpi (1930), Tortosa (1943), Delicias (1942), en el Paseo de Extremadura, el cine Albarrán (1943) (Crespo, 1974b; Sánchez Fernández, 2013).

A la importancia del cine como elemento de ocio, hay que añadir su valor como elemento de transformación de paisaje urbano. La mayoría de sus locales fueron construidos con la exclusiva finalidad de disponer de grandes salas para la proyección de películas pero su calidad arquitectónica resultó sobresaliente, muchos fueron realizados por arquitectos de prestigio y todos ellos contribuyeron a renovar la fisionomía de los espacios en los que se asentaron y a crear nuevas centralidades en torno al disfrute de la función a la que daban cabida. El estilo Modernista, no ajeno a otras realizaciones arquitectónicas del Madrid de principios de siglo, se encuentra muy bien representado en los cines Doré, Royaltí y Salón de Madrid, que cubrieron sus fachadas con enrevesados detalles vegetales, afiladas aristas y abombados medallones. La llegada de los 1930 y el mimetismo con los «grandes palacios» del cine de la Gran Vía, dejaron paso al funcionalismo y el racionalismo arquitectónico, más preocupado por la pureza de las líneas y la óptima adaptación del edificio a su función. Sus ejemplos, mayores que en el caso anterior, tienen entre sus mejores referentes en el cine Barceló y en el cine San Carlos, al comienzo de la calle Atocha (Sánchez Fernández, 2013).

Todas estas inauguraciones ampliaron el número de locales en la ciudad hasta los 94 en 1945 lo que unido a la amplitud de los horarios del cine -en particular los de los cines de sesión continua- y al paulatino afianzamiento de las jornadas reguladas en los trabajos, permitieron el acceso a esta diversión a un mayor número espectadores. Así mismo, la proyección continuada de películas del extranjero contribuyeron a popularizar nuevas modas, comportamientos y valores sociales entre la población (Báez y Pérez de Tudela, 2012), y afianzar el componente educativo del cine a través de la proyección de «informaciones documentales [...] de todo el mundo» que permitían al «arquitecto, el geógrafo, el médico, el naturalista [...] y al público más profano» completar «su cultura, sin notar por ello fatiga» (Gran Vía, Memoria de Madrid, 1933: 1). 
La expansión de los cines en los nuevos barrios y en la aglomeración urbana madrileña a partir de los años 1950

Hasta bien entrada la década de los 1960, el cine mantuvo su importancia entre las formas de ocio de los españoles y el crecimiento del número de locales y el auge de la afluencia a las salas fueron fenómenos comunes en todo el país (Álvarez Monzonillo, 1993). En el caso de Madrid, estas tendencias se vieron apoyadas por el crecimiento demográfico que afectó a su población durante las décadas posteriores a la Guerra Civil y por la creación de nuevos barrios en los municipios anexionados entre 1948 y 1955. Madrid pasó de poco más de medio millón de habitantes en 1930 a 2 millones en 1960. Todo ello permitió ampliar el espacio de exhibición del cine y articular sus dinámicas con el crecimiento que experimentaba una ciudad que desbordaba los límites de su término municipal para convertirse en área metropolitana.

Entre 1945 y 1955 se abrieron 63 nuevos cines en la ciudad cuya distribución por el entramado urbano completó los espacios de exhibición del centro y consolidó la presencia de los cines de la periferia (Crespo, 1974a; Crespo, 1974b). En este espacio la expansión de la actividad se produjo a partir de pequeños cines de sesión continua que se llenaban «con la chavalería del barrio» (González, 2007: 115) y con locales de grandes aforos instalados en las calles principales, como el cine América del Paseo de las Delicias (1.522 localidades) o el Savoy de Bravo Murillo (1.044 localidades), entre otros (Crespo, 1974b). Así mismo, los nuevos locales construidos en esta fase permitieron ensayar con nuevas tipologías constructivas y modalidades de negocio para la exhibición cinematográfica. En este sentido, el cine Roxy, construido en 1952 en la calle Fuencarral se adelantaría al fenómeno de la multisala al combinar la sesión continua y las funciones de tarde/noche en dos salas idénticas (González, 2007). Del mismo modo, la tipología de los «autocines» trató de progresar en la periferia de Madrid con el Motocine Barajas que fue construido en 1959 cerca de la Alameda de Osuna y muy próximo por tanto a los que podrían haber sido sus principales demandantes, los militares estadounidenses de la base aérea de Torrejón de Ardoz. Con todo, quizás por su novedad o por la escasa afluencia, esta instalación apenas permaneció abierta unos años después de su inauguración y tras la reordenación urbana de este espacio en fechas recientes se ha perdido cualquier vestigio de su anterior presencia (Sánchez Fernández, 2013) (figura 4).

En 1965, funcionaban en España 8.041 salas de cine, de las cuales algo menos de 400 se concentraban en la provincia de Madrid (Álvarez Monzonillo, 1993). La capital alcanzó su cenit en 1966 con 208 locales, mientras que los 
crecimientos del área metropolitana habían incrementado la presencia de esta actividad hasta los 154 locales en 1965, cifra que se incrementaría en los años posteriores (197 en 1970 y 207 en 1972) (Crespo, 1974a). En esos años, la evolución del espacio cinematográfico madrileño estará condicionada por los cierres provocados por la crisis de afluencia que afectó a esta forma de ocio desde mediados de los 1960, por la mayor presencia de esta actividad en los municipios del área metropolitana y por los cambios que afectaron al negocio de la exhibición a partir de la generalización del formato multisala y la articulación de su actividad con la de los centros comerciales, como veremos en el siguiente apartado.

FIGURA 4

EL MOTOCINE BARAJAS. PLANTA DEL CONJUNTO (FRAGMENTO)

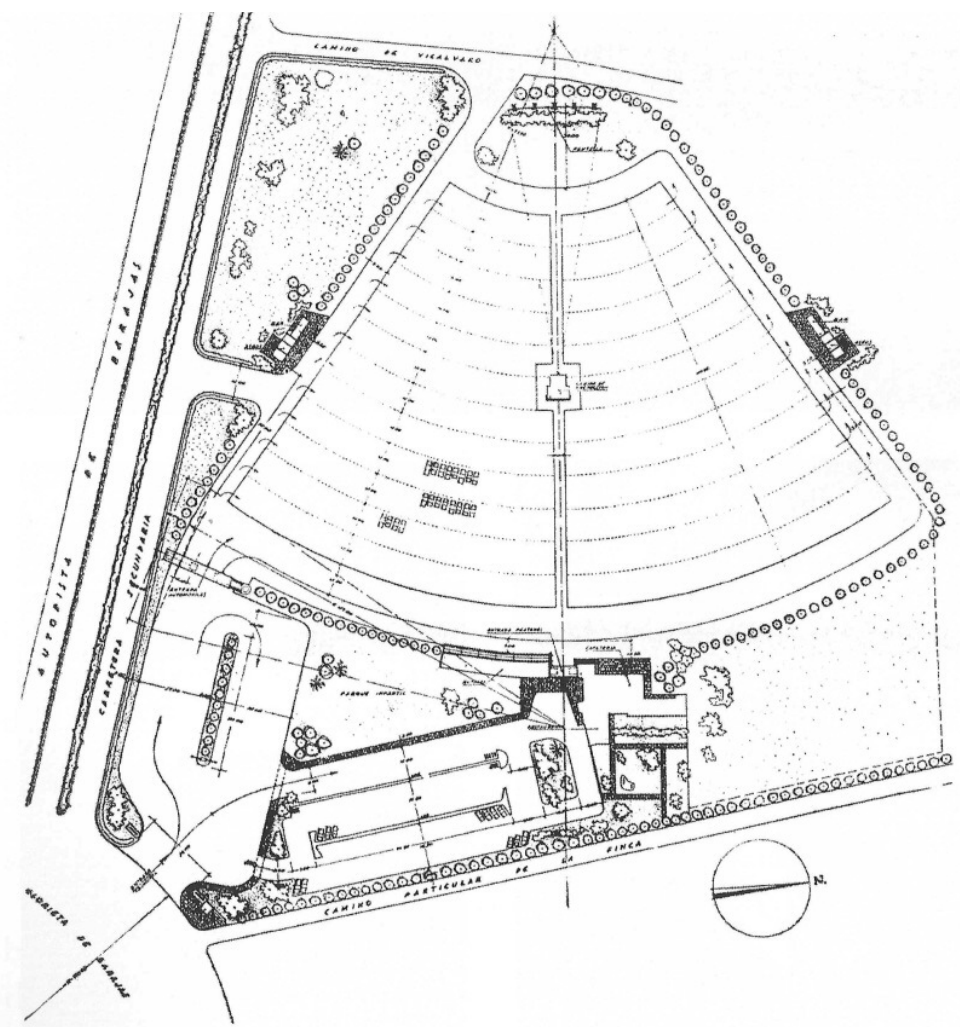

Fuente: Sánchez Fernández (2013).

Estudios Geográficos, Vol. LXXVII, 280, pp. 115-153, enero-junio 2016 ISSN: 0014-1496, eISSN: 1988-8546, doi: 10.3989/estgeogr.201605 
La PÉRDida DE lOCALES DE CINE EN MADRID ANTE El ACCESO DE LAS MASAS A NUEVAS FORMAS DE OCIO

A partir de 1965 la aparición de nuevas formas de ocio y el cambio en los modos de vida redujeron la importancia del cine entre las formas de diversión de los españoles. El aumento del poder adquisitivo posibilitó el acceso a nuevos productos de consumo y el cambio de modas y de costumbres facilitó la expansión de nuevas alternativas para el disfrute del tiempo libre. «Salir los fines de semana al campo», «ver películas en casa», «asistir a eventos deportivos»y la «realización de viajes turísticos», comenzaron a convertirse en las actividades principales para el disfrute del ocio. Así mismo, el aumento del nivel de formación medio de la población y la mayor disponibilidad de información, contribuyeron a extender el consumo hacia productos y servicios culturales antes minoritarios y a difundir prácticas de entretenimiento individual en torno a la lectura, el coleccionismo o la práctica del deporte. Entre todas ellas, la difusión de la televisión y de los magnetoscopios desde los años 1960, posibilitaron el desarrollo de nuevas de formas entretenimiento doméstico que alcanzarán una gran popularidad entre los españoles. Las retransmisiones de Televisión Española comenzaron a realizarse de manera regular desde 1956 con programaciones que incluían largometrajes, obras de teatro, espectáculos deportivos, concursos y otros programas de entretenimiento. Por entonces la televisión estaba presente en 3.000 hogares en España, pero el incremento del poder adquisitivo y el paulatino abaratamiento de los precios posibilitaron que esta se extendiera hasta el 70\% de los hogares a finales de los años 1960 y al $80 \%$ en 1975 , lo que supuso una fuerte competencia para la actividad del cine (Álvarez Monzonillo, 1993; INE, 2003; González, 2007: 115-118). En la actualidad, su presencia llega prácticamente al 100\% de los hogares (99\% en 2008) y las alternativas que ofrece para el ocio doméstico se han visto reforzadas por la expansión de otros electrodomésticos de consumo (DVD, reproductores, etc.), el crecimiento y diversificación de la programación, la generalización de internet y de sus usos para fines relacionados con el ocio (INE, 2008).

La caída de la afluencia a las salas y el cierre de locales comenzaron a manifestarse en España desde mediados de los años 1960, alcanzando su mayor intensidad en la década de 1980 a 1990. Entre 1964 y 1972 el número de salas a nivel nacional se redujo en algo menos de mil y la afluencia cayó desde los 400 millones de espectadores en 1966 a 225 en 1971 (Crespo, 1974a; Álvarez Monzonillo, 1993) (figura 5). En la ciudad de Madrid y en otras urbes españolas, el cierre de locales se vio intensificado por los procesos de especulación del suelo, lo que favoreció la venta de los terrenos de los locales como medida de solución 
para contrarrestar la caída de rendimientos del negocio. Desde 1966 hasta 1970, cerraron 15 salas en la ciudad, 13 a lo largo de los 1970 y 56 durante los 1980 (González, 2007). Aunque en los 1990 y los primeros años del 2000 la caída del número locales de cine se ralentizó de manera generalizada en Madrid, y se registró un leve incremento por la expansión del cine en los grandes equipamientos comerciales construidos en el área metropolitana y supra metropolitana -en sintonía con las dinámicas que tuvieron lugar en otras aglomeraciones españolas (Ponce y Espinosa, 2013; Álvarez Monzonillo y López Villanueva, 2006; García Escalona, 2000; Ruiz Palomeque et al., 2000)-, la pérdida de locales en el centro, en los barrios del ensanche y de las periferias continuó siendo importante (Instituto de la Cinematografía..., 2003) (figura 6). Por otro lado, en los años recientes, el estallido de la crisis económica y un incremento de la competencia por la aparición de una nueva generación de equipamientos para los hogares y el auge de la "piratería» han acentuado la caída de la afluencia del cine y con ello el cierre de locales en todo el país (Álvarez Monzonillo y López Villanueva, 2006).

FIGURA 5

EVOLUCIÓN DEL NÚMERO DE CINES Y ESPECTADORES EN ESPAÑA ENTRE 1965/66 Y 2013
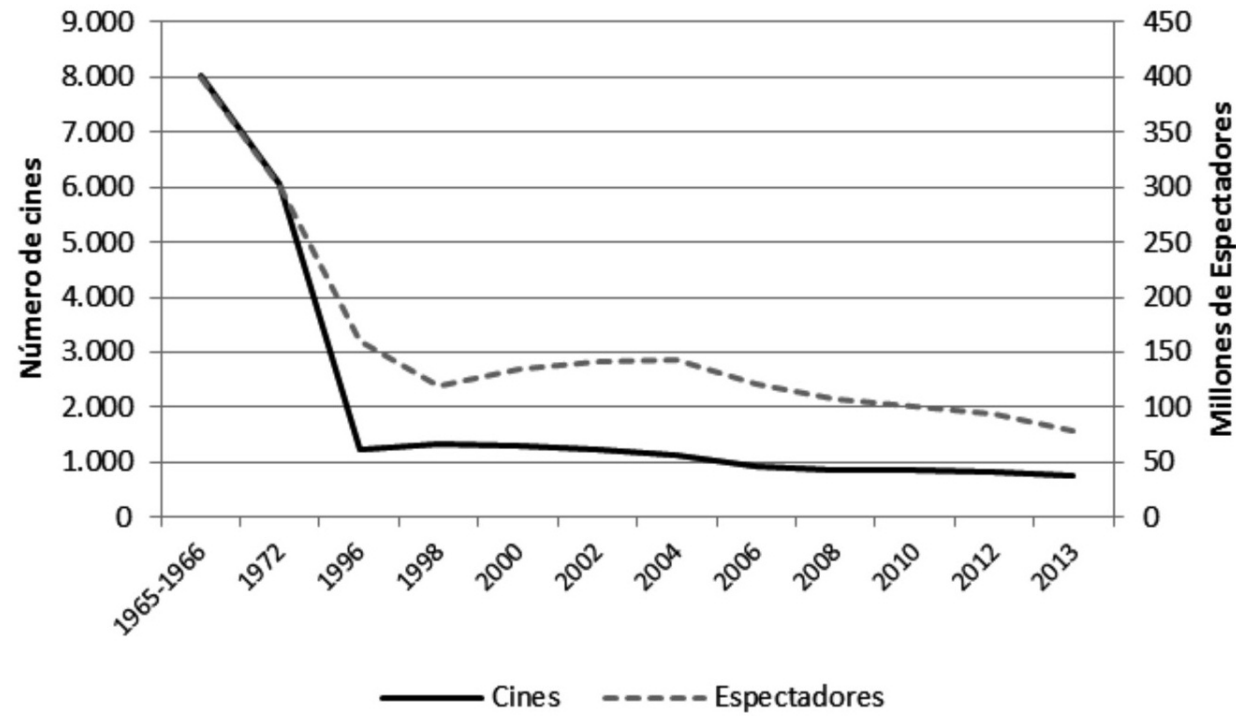

Fuente: Crespo (1974a); Álvarez Monzonillo (1993); Ministerio de Educación, Cultura y Deportes (19921995/2005-2012); ICCA-MCU (2003); AIMC (2013); y EFE (2014). 
FIGURA 6

EVOLUCIÓN DEL NÚMERO DE CINES Y ESPECTADORES EN MADRID ENTRE 1997 Y 2012

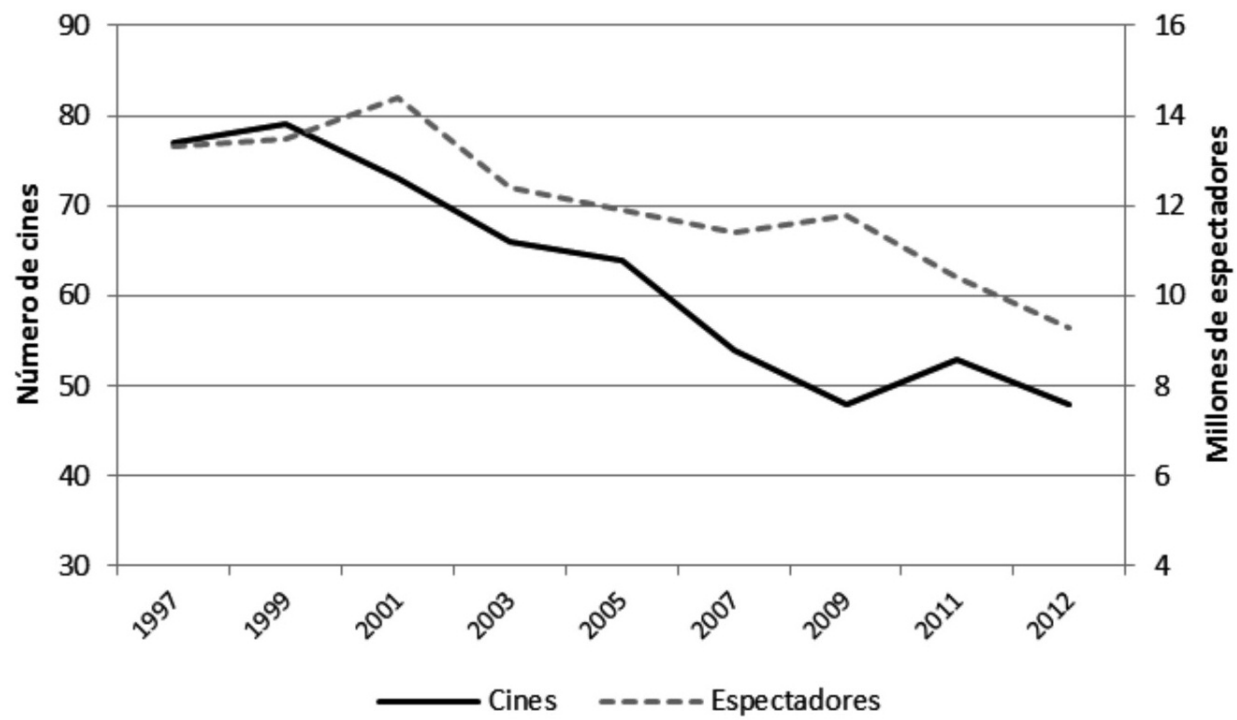

Fuente: ICCA-MCU (2003) y AIMC (2013).

Según datos del último Censo de Cines, en Madrid funcionaban 42 cines en $2013^{7}$, lo que supone una pérdida de 166 locales con relación al máximo de 208 locales alcanzado en 1966. Tomando como referencia la división administrativa de 1987 y las zonas de mayor concentración de cines antes del comienzo de la crisis, se observan perdidas comunes en todos los distritos, aunque con especial intensidad en los de Centro, Salamanca, Tetuán y Chamberí, donde esta actividad alcanzó un mayor protagonismo en el pasado, pero que han sido afectados por procesos de fuerte envejecimiento demográfico y pérdida de población. En el primero, en el distrito Centro, han cerrado la mayor parte de los cines de la Gran Vía, los que rodeaban a la

7 Todos los datos numéricos sobre negocios de cine en Madrid que se exponen a continuación proceden de AIMC, 2013. 
Puerta del Sol por el norte y por el sur, y los que se situaban entre la Gran Vía y el distrito de Chamberí, a pesar de los esfuerzos puestos en marcha por la EMV y el Ayuntamiento para dinamizar la actividad en esta zona a través del Plan URBAN de recuperación de «Los itinerarios de cines y de teatros» y de mejora de las aceras de la Gran Vía a finales de los años 1990 (Herraez, 2000). Chamberí es después del Centro el distrito que más locales ha perdido, especialmente en el área de concentración de esta actividad que se formó en el entorno de la Glorieta de Bilbao y la calle de Fuencarral, y en diferentes espacios diseminados por Alberto Aguilera y las calles del interior. Por último, en el distrito de Salamanca los cierres han afectado a los cines que se extendieron por las calles de Goya y Alcalá, y desde la Plaza de Manuel Becerra hasta Ventas; mientras que en Tetuán, el cine ha desaparecido completamente del distrito.

En las periferias, las perdidas también han sido importantes, pero la situación final es desigual. Los cines que se instalaron a partir de los años 1940 en calles principales como General Ricardos (Carabanchel), Paseo de Extremadura (Latina), Paseo de las Delicias (Arganzuela), Avenida de la Albufera (Vallecas) o el tramo de la calle Alcalá a partir de la Plaza de Ventas (antigua carretera de Aragón), han cerrado paulatinamente, hecho que también se manifiesta en los casos de los pequeños locales de exhibición que se dispersaron al interior de los barrios. Sin embargo, el crecimiento de la ciudad y las operaciones de remodelación desarrolladas en algunas de estas zonas han posibilitado una recuperación de esta actividad en "Centros Comerciales y de Ocio». Estos son los casos, entre otros, de los cines Yelmo Islazul y Cinesa La Gavia, vinculados a la construcción de los PAU de Carabanchel y de Vallecas; del Cine Cité y de Cinesa Príncipe Pío, construidos durante las operaciones de recuperación urbana y de creación de nuevas centralidades en Arganzuela (Pasillo Verde y Operación Méndez Álvaro); o del Abaco Villaverde, del Centro Comercial Los Ángeles que fue inaugurado tras la rehabilitación del barrio de Rosales (figura 7 ).

Con todo, la pérdida de cines en Madrid ha sido la tónica dominante desde mediados de los años 1960. El destino de los locales de exhibición ha sido diverso en función de las características arquitectónicas de cada uno de ellos y del dinamismo de sus espacios de ubicación, hechos que han determinado en última instancia su adaptación a la nueva realidad. En la Gran Vía, la posibilidad de continuar aprovechando las rentas de situación y de la arquitectura de los locales ha permitido la transformación de algunos de ellos en teatros, como los cines Rialto, Gran Vía, Lope de Vega y Coliseum, 
FIGURA 7

EVOLUCIÓN DEL NÚMERO DE CINES POR DISTRITOS ENTRE 1991 Y 2013

- 2013 - $2000=1991$

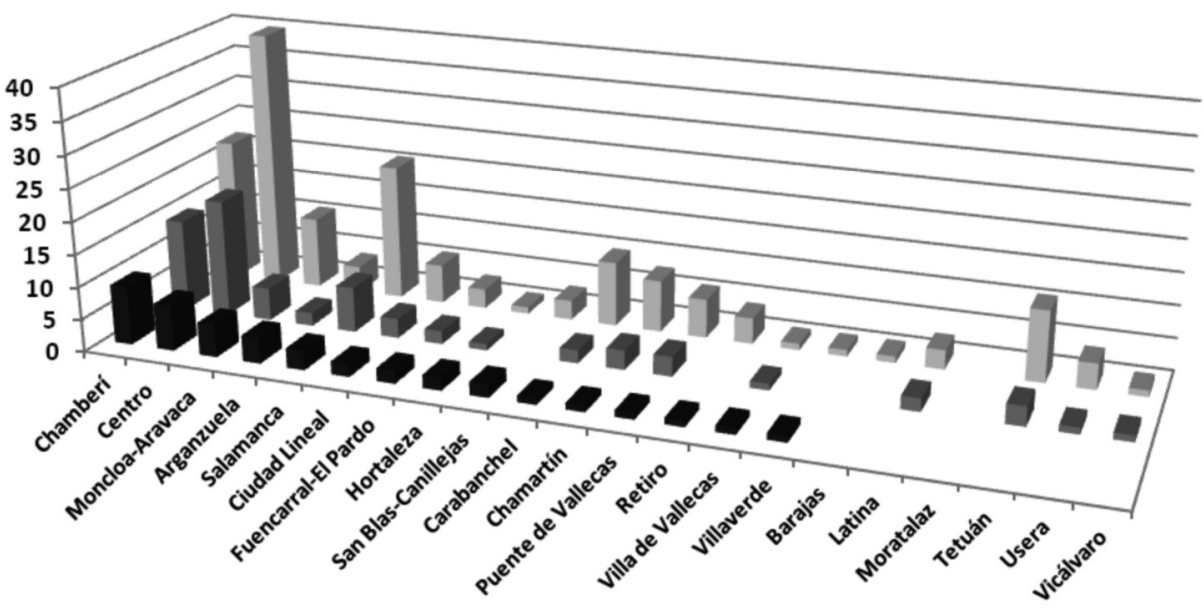

Fuente: Almax (1991); Jiménez Hernández (2000); y AIMC (2013).

entre otros ${ }^{8}$, coincidiendo con el auge que ha tenido este espectáculo y los musicales al estilo de «Broadway» en la ciudad en los últimos años. En otros casos, la amplitud de los locales ha posibilitado la instalación de nuevos negocios -bancos, agencias de viajes-, o la fragmentación de su espacio para el aprovechamiento combinado por restaurantes, tiendas de ropa, zapaterías y otros comercios al por menor (figura 8). Finalmente, son muchos los casos que tras nuevos usos fracasados o sin utilización desde su cierre, permanecen abandonados y en avanzado estado de deterioro, lo que acrecienta la preocupación social por tratarse en algunos casos de edificios con destacados valores patrimoniales.

8 Teatro Rialto Movistar, Gran Vía nº 14 (Cine Rialto, 1930); el Teatro Compac Gran Vía, Gran Vía no 66 (Cine Gran Vía, 1949); el Teatro Coliseum, Gran Vía n 78 (Cine Coliseum, 1933). 
FIGURA 8

ANTIGUO CINE AZUL RECONVERTIDO A NUEVOS USOS (C/ GRAN VÍA)

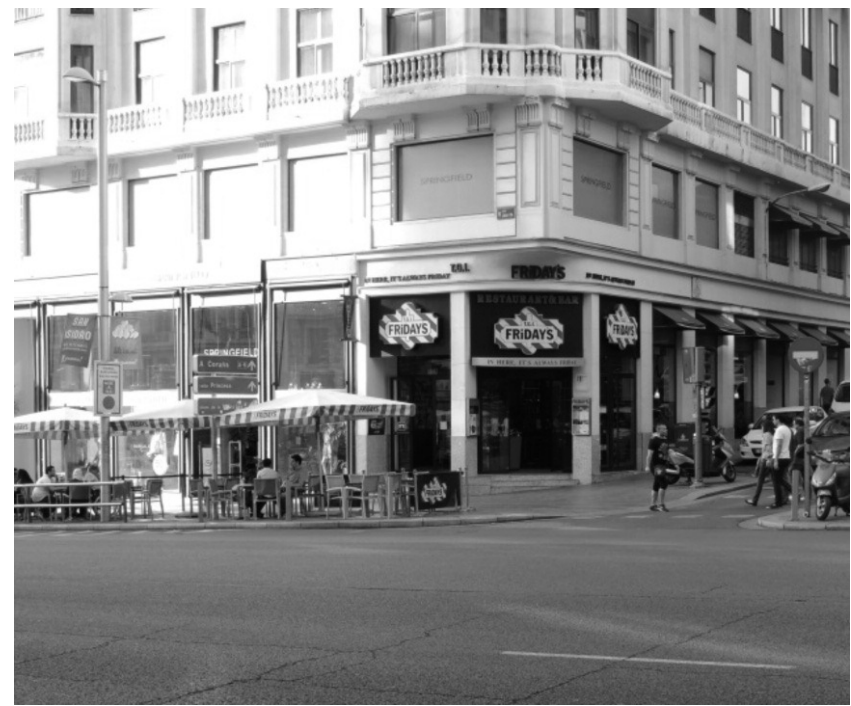

Fuente: fotografía capturada en 2014

CARACTERÍSTICAS DEL ESPACIO DE EXHIBICIÓN ACTUAL: LA IRRUPCIÓN DE LAS MULTISALAS

Los 42 cines que funcionaban en Madrid en 2013 manifiestan los procesos de renovación que han afectado la actividad a partir del desarrollo del fenómeno de la «multisala», la implantación de las nuevas tecnologías de exhibición y la renovación en las formas de consumo del cine con su integración a la actividad de los «Centros Comerciales». Así mismo, con el fin de aportar nuevos atractivos para la demanda se han puesto en marcha estrategias novedosas que buscan una integración del sector con las formas de consumo cultural que se desarrollan en diferentes instalaciones de la localidad. Todo ello ha reconfigurado el espacio de exhibición en la ciudad al reordenar la distribución de las salas y de los aforos por el entramado urbano, e introducir una nueva fisionomía del paisaje del cine en la ciudad que constituye un reflejo de los cambios que han afectado a las formas de consumo de ocio de los madrileños en la posmodernidad (García Escalona, 2000) y los fenómenos de cambio urbano que han afectado a Madrid a partir del vaciamiento funcional del centro y la ex- 
pansión de la actividad y de la población hacia el área periférica y metropolitana (Ferrer, 2003; Zárate, 2003; Rodríguez, 2004; Vidal y Fernández, 2012), en donde se concentra buena parte de la actividad cinematográfica de la región (Gámir, 2001; Prieto Flores, 2003).

\section{Distribución y caracterización actual de los locales del cine en la ciudad de Madrid}

La distribución de locales por el conjunto de la ciudad reproduce la pervivencia del centro urbano como área de máxima concentración de la actividad aunque el reparto de cines se muestra diferente respecto a épocas anteriores. Los cierres de las últimas décadas han hecho de Chamberí el distrito con mayor número de locales (9) en detrimento de la posición hegemónica que mantuvo a lo largo del siglo xx el distrito Centro (7). En el interior de cada una de estas demarcaciones, el mayor número de locales se concentra en los lugares donde esta actividad alcanzó un mayor protagonismo en épocas anteriores, como las calles de Fuencarral y Luchana (en Chamberí), el eje de Gran VíaPlaza de Callao (en Centro) y en otros espacios diseminados por el interior de cada uno de ellas. Hasta los límites que establece la M-30, la concentración de locales se muestra diferente en función del distrito considerado. En Retiro y Chamartín, se mantienen los cines de la calle Narváez 42 (Renoir Retiro) y de Pradillo 4 (Morasol), mientras que en Salamanca, Arganzuela y Moncloa-Áravaca, la presencia de esta actividad se manifiesta en tres, cuatro y cinco locales respectivamente. En estos casos la exhibición de filmes se realiza en los antiguos cines que aún funcionan en la Guindalera, Argüelles y Goya; en locales situados en complejos comerciales y culturales (Cine Príncipe Pío, Cine Cité de Méndez Álvaro o Sala Iberia en la Casa de América) y en parques públicos que han adecuado su espacio para la proyección de filmes durante el verano (cine del Parque de la Bombilla y cine Open Air en el auditorio del Parque Enrique Tierno Galván).

Fuera del anillo de la M-30, funcionaban en 2013 doce cines, ocho en los distritos del norte-noreste y cuatro en los del sur-sureste. En ambos espacios, la presencia de cines en centros comerciales y de ocio es predominante, pero en el caso de los primeros también se detecta la presencia de un cine de barrio (el Mirasierra-Paraiso, de Fuencarral-El Pardo) y del cine de verano del Parque Calero (en Ciudad Lineal). En definitiva, la distribución del número de locales en la ciudad continúa siendo mayoritaria dentro de los límites de M-30, especialmente en Chamberí y Centro, y de manera más desigual en los 
espacios alejados de estos, manifestando la capacidad de atracción funcional de todo este espacio para parte de la aglomeración, incluidos viajeros y turistas.

En los distritos que se desarrollan a partir de la M-30 y hasta los límites municipales, el número de locales es mucho menor y su presencia está vinculada a la actividad reciente de los «Centros Comerciales» y a algunos cines comerciales convencionales. Sin embargo, la distribución de pantallas y de los aforos por la ciudad, merman la importancia de centro como lugar de desarrollo de la actividad en favor de las periferias, como se verá en los siguientes apartados.

\section{Caracterización de los locales por tipo de negocio}

Atendiendo a los tipos de negocio bajo los cuales se desarrollan los cines madrileños el espacio de exhibición de la ciudad se puede clasificar en cuatro categorías: los «cines ubicados en Centros Comerciales y de Ocio», los «cines de verano», los «cines de arte y ensayo y/o vinculados a actividades de centros culturales», y los «cines comerciales convencionales». La importancia de cada una de estas categorías en la ciudad es desigual, lo mismo que su distribución por el espacio urbano. Los cines ubicados en «Centros Comerciales y de Ocio» representan el 26\% de los locales de exhibición y su distribución se concentra principalmente en los distritos de la periferia (9) y en los bordes de la Almendra Central (2). En ambos casos la presencia de estos locales se vincula a la construcción de nuevos espacios residenciales y a las reformas urbanas que han permitido la expansión de los centros comerciales y de los cines como parte integrante de ellos.

La segunda categoría se integra por los cines de verano que suman un total de 3 y representan el 7\% de los locales de exhibición en la ciudad. Se distribuyen en tres espacios verdes ubicados en dos parques de borde de la Almendra Central (La Bombilla y Enrique Tierno Galván) y en el polideportivo al aire libre del Parque Calero, en el distrito de Ciudad Lineal. El resto de cines de la ciudad representan el $66 \%$ de sus locales de exhibición, de los cuales, los de arte y ensayo y/o vinculados a actividades de centros culturales participan con ocho locales (el 19\%) y los cines comerciales convencionales con veinte (el 47\%). En ambos casos, la ubicación de los locales es mayoritaria dentro de los límites de la M-30, especialmente en el centro urbano, y únicamente el cine del Centro Cultural Paco Rabal (Vallecas) es ajeno a esta pauta (figura 9). 
FIGURA 9

DISTRIBUCIÓN DE LOS DIFERENTES TIPOS DE CINES EN 2013

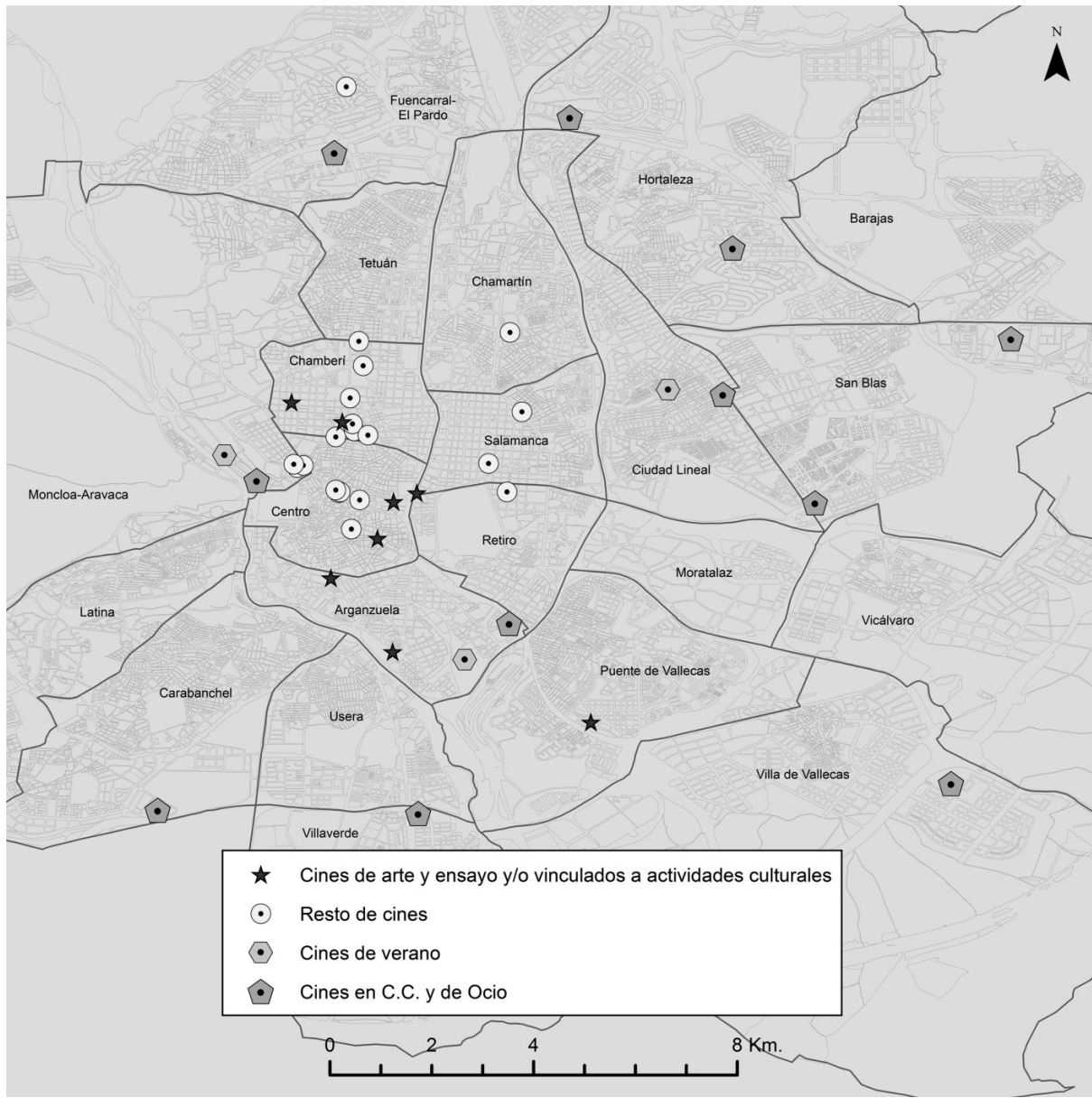

Fuente: AIMC (2013); y Dirección General del Catastro Madrid (2014).

\section{El crecimiento de las pantallas y su concentración en los nuevos paisajes terciarios de la periferia urbana}

La caída de la afluencia al cine y la necesidad de buscar nuevas fórmulas para adecuarse a la situación de la demanda y de los nuevos tiempos, fomentaron la implantación de los formatos «multisala» en los cines españoles a partir 
de los años 1980. Esta nueva modalidad de negocio permitía a los empresarios del sector aplicar criterios de explotación más adecuados a la demanda real, disminuir los gastos de mantenimiento que conllevaban las grandes salas y disponer de una cartelera más ágil y diversificada para los gustos de los espectadores. Así mismo, abría la oportunidad de introducir reformas en los cines con el fin de mejorar su confortabilidad y ofrecer un formato de negocio flexible y atractivo para su integración con los centros comerciales y de ocio (Álvarez Monzonillo, 1993) que se fueron instalando en las áreas metropolitanas y supra metropolitanas en el contexto de consolidación del modelo de ciudad dispersa.

En «la mermada cartelera madrileña», los Minicines Alphaville, de la calle Martín de los Heros, fueron los primeros en desarrollar este formato de negocio en 1977. Ofertaban películas de calidad en versión original, en varias salas de reducido tamaño (cuatro a finales de la década) que tenían aforos para algo más de cien de espectadores. A mediados de los años 1980, los cines Renoir ampliaron este tipo de negocio en la ciudad con cinco nuevas salas y en los años siguientes, los cines del centro y de los barrios comenzaron a transformarse en «multisala» (González, 2007: 118). La progresión de este formato de exhibición en la ciudad fue generalizada en los años posteriores, al igual que en el resto del país, lo que permitió compensar el cierre continuado del número de locales que se estaban produciendo de forma paralela, con una ampliación general de las pantallas hasta fechas recientes.

En 2010, España era el tercer país de la Unión Europea por número de pantallas $(4.080)^{9}$, y en 2013 el desarrollo de formas evolucionadas del formato «multisala», como los cines Megaplex y Multiplex ${ }^{10}$, afectaba ya al $34.7 \%$ y al $6.8 \%$ de los locales. En la ciudad de Madrid, el número de pantallas ha mantenido una tendencia de crecimiento hasta $2010^{11}$, momento a partir del cual la crisis económica ha acentuado los procesos de cierres de locales. Con todo, en 2013, las pantallas en funcionamiento eran 243, lo que representa el $6.3 \%$ de todo el país (3.813) y un ratio de 2,3 pantallas por cada 100 madrileños. Su distribución por la ciudad muestra la elevada concentración en los distritos periféricos frente a los centrales, en donde el mayor número de

\footnotetext{
${ }^{9}$ Precedido de Alemania (4.699) y Francia (5.465). (AIMC, 2013).

10 Multiplex: locales que poseen 6 o más pantallas y 2.000 o más butacas; Megaplex: locales que poseen 15 o más pantallas y 4.000 o más butacas (Álvarez Monzonillo y López Villanueva, 2006).

${ }^{11}$ En este año funcionaban 284 pantallas en la ciudad, frente a las 216 de 1997 (Ministerio de Educación, Cultura y Deporte, 1992-1995/2005-2012).
} 
locales y las reformas operadas para implantar el formato «multisala» no han podido competir en número de pantallas con los cines construidos en los centros comerciales y de ocio. Siguiendo las tipologías de negocios definidas en el apartado anterior los cines ubicados en estas instalaciones concentraban el 53\% de las pantallas del municipio (131 en términos absolutos). Dentro de estos, el Cinesa Manoteras y el Cine Cité ocupan la primera y segunda posición, con 20 y 16 pantallas respectivamente, y el Cine Dreams la tercera, con 15. Por debajo de ellos, el resto de los locales de este tipo se ordenan en dos de trece pantallas, dos de diez y cuatro con valores entre ocho y nueve.

\section{FIGURA 10}

DISTRIBUCIÓN DE PANTALLAS ENTRE LOS CINES DEL MUNICIPIO EN 2013

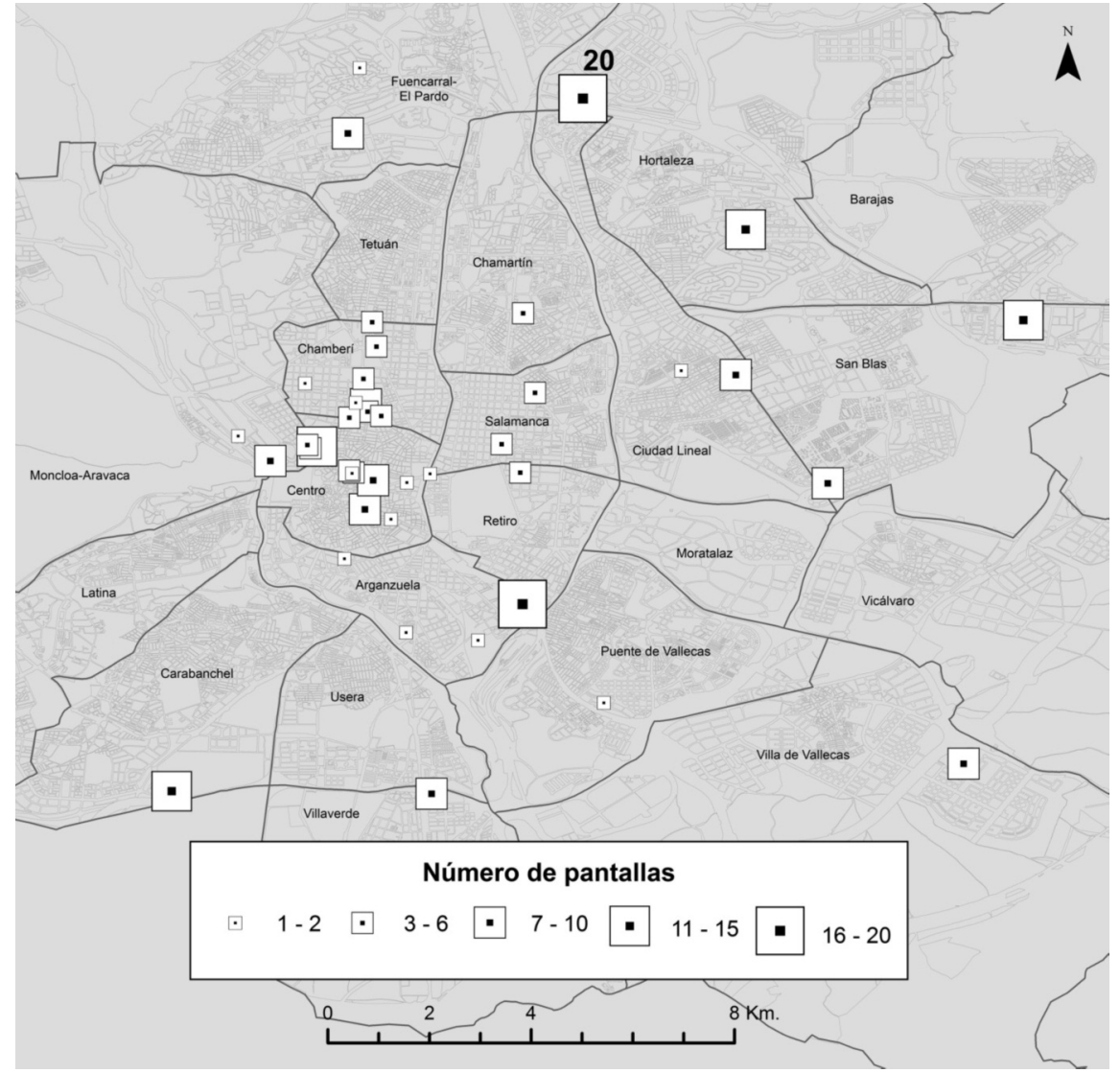

Fuente: AIMC (2013); y Dirección General del Catastro Madrid (2014).

Estudios Geográficos, Vol. LXXVII, 280, pp. 115-153, enero-junio 2016

ISSN: 0014-1496, eISSN: 1988-8546, doi: 10.3989/estgeogr.201605 
Los cines de verano de la Bombilla, de Parque Calero y del Tierno Galván, aportan el $1 \%$ de las pantallas del municipio, mientras que los cines de arte y ensayo y/o vinculados a las actividades de centros culturales, el 3\% (9 pantallas). Salvo en el caso del cine Doré, con dos salas de exhibición dentro del local, se trata de cines «monosala», los únicos que quedan de este tipo en el municipio. En los cines comerciales convencionales las pantallas representan el $40 \%$ del total de la ciudad (99 pantallas). Once de ellas se sitúan en el cine Princesa, el que tiene mayor número, junto con los cines Acteón y Yelmo, de nueve y el Cinesa Proyecciones de Fuencarral, con ocho. El resto, con valores entre 3 y 6 pantallas, se distribuye de manera desigual por diferentes distritos centrales y periféricos. Por lo tanto, aunque la presencia de locales del cine continua siendo mayoritaria dentro del anillo de la M-30, especialmente en el centro, las pautas en la distribución de pantallas muestran una acusada concentración en los distritos de la periferia, hecho que demuestra la importancia que ha adquirido esta forma de diversión en el marco de los centros comerciales y así mismo, el desplazamiento de los principales focos de su demanda hacia los espacios periféricos, donde se concentran una buena parte de la población de la ciudad (figura 10).

\section{Grandes salas y nuevas tecnologías como estrategias para incrementar el valor de la experiencia de ocio}

El crecimiento del número de pantallas en Madrid y su expansión hacia la periferia de la ciudad han provocado un desplazamiento generalizado del aforo hacia los Centros Comerciales y de Ocio, hecho que se ha visto favorecido por la popularización en estos espacios de un nuevo concepto de exhibición en salas de grandes dimensiones dotadas de las mejores condiciones de confort y de tecnologías para la exhibición (Álvarez Monzonillo y López Villanueva, 2006). Este proceso se ha desarrollado en paralelo a la pérdida generalizada de aforo en la ciudad a partir de 1972, por lo que su desarrollo ha resultado fundamental para la configuración del espacio de exhibición de la ciudad actual. En esta fecha, las localidades que ofertaban los cines madrileños llegaron al techo de las 191.846 tras varias ampliaciones sucesivas a lo largo del siglo xx (Crespo, 1974a). Desde entonces la caída de la afluencia ha reducido el valor de la oferta de la hasta 57.471 localidades en 2013, lo que supone una pérdida de 134.375 con relación al valor de 1972 y un descenso del número de butacas por cada mil habitantes desde las 192 a las 57.

El reparto del aforo de 2013 entre las categorías de tipos de cine se concentra en un 50\% (28.795 localidades) en los ubicados en los Centros Comercia- 
les y de Ocio, localizados mayoritariamente en los distritos exteriores al anillo de la M-30 y en dos centros construidos en los bordes de la Almendra Central. Dentro este grupo, dos de ellos, el Cinesa Manoteras y el Cine Dreams, se clasifican bajo la categoría Megaplex al disponer de capacidades por encima de los 4.000 espectadores y más de 15 pantallas. Por debajo de ellos, seis establecimientos se encuadran bajo el formato Multiplex, y los tres restantes (Alcalá Full HD, Cinesa Las Rosas y Abaco Villaverde) disponen de aforos entre 1.228 y 1.772 localidades y entre 8 y 10 pantallas. El cine digital está presente 107 de las 131 pantallas que ofrecen estos cines y las opciones 3D en 53, lo que supone el $64 \%$ y el $68 \%$ con relación a la presencia total que tienen ambas tecnologías de la exhibición en el conjunto de la ciudad.

\section{FIGURA 11}

TIPOS DE CINES, PANTALLAS, AFORO Y DE NUEVAS TECNOLOGÍAS PARA LA EXHIBICIÓN EN LOS CINES DE MADRID, 2013 (PORCENTAJE SOBRE VALORES TOTALES)

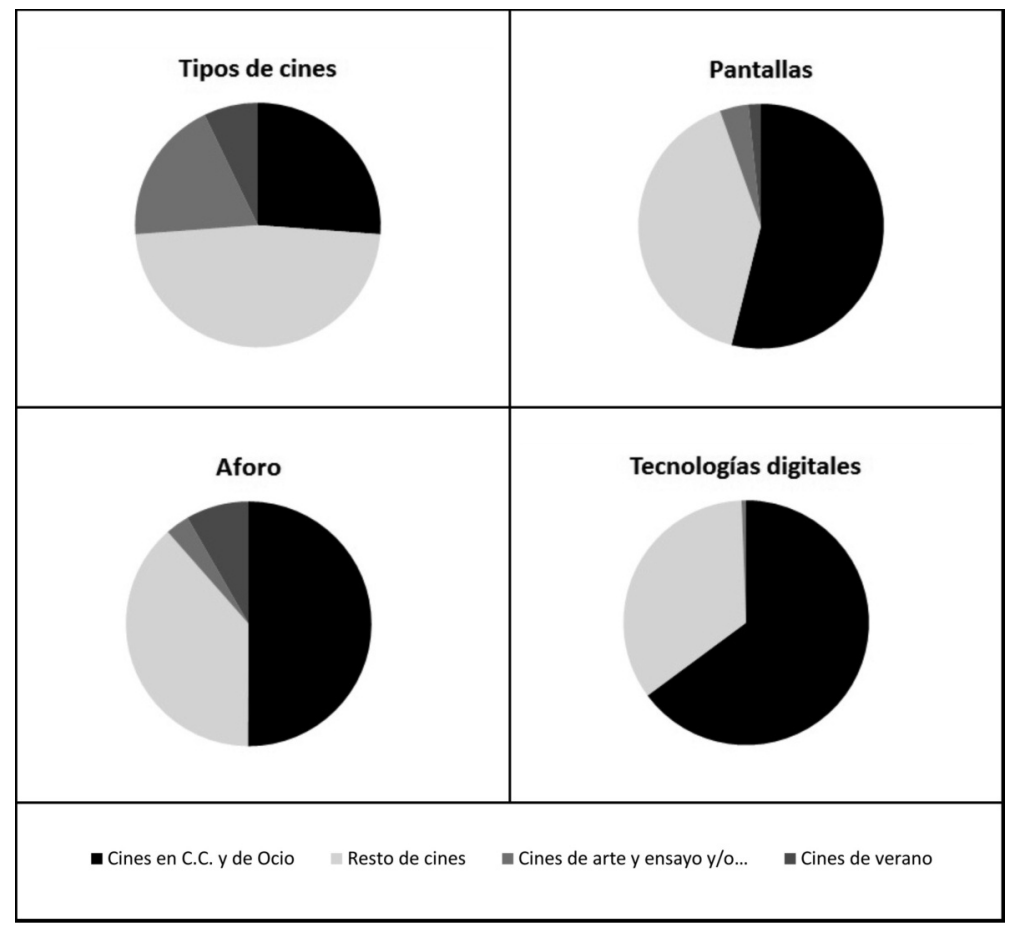

Fuente: AIMC, (2013). 
Entre los cines comerciales, los mayores aforos se concentran en los distritos de Centro y Chamberí, especialmente en los cines de entorno de la Gran Vía y de la Glorieta de Bilbao. Solamente uno de ellos, el cine Acteón de la calle Montera, con 9 pantallas y capacidad para 3.031 espectadores, puede ser categorizado como cine multiplex, mientras que el resto se ordena en dos umbrales de entre 1.840 y 1.015 localidades (nueve cines) y entre 987 y 348 (diez cines). En conjunto la oferta de esta tipología representa el 38\% del aforo del municipio (22.091 localidades) y el grado de implantación de las tecnologías digitales y 3D está presente en 57 y en 23 salas respectivamente (el 34\% y el $29 \%$ con relación al total de la ciudad).

FIGURA 12

\section{DISTRIBUCIÓN DEL AFORO ENTRE LOS CINES DEL MUNICIPIO EN 2013}

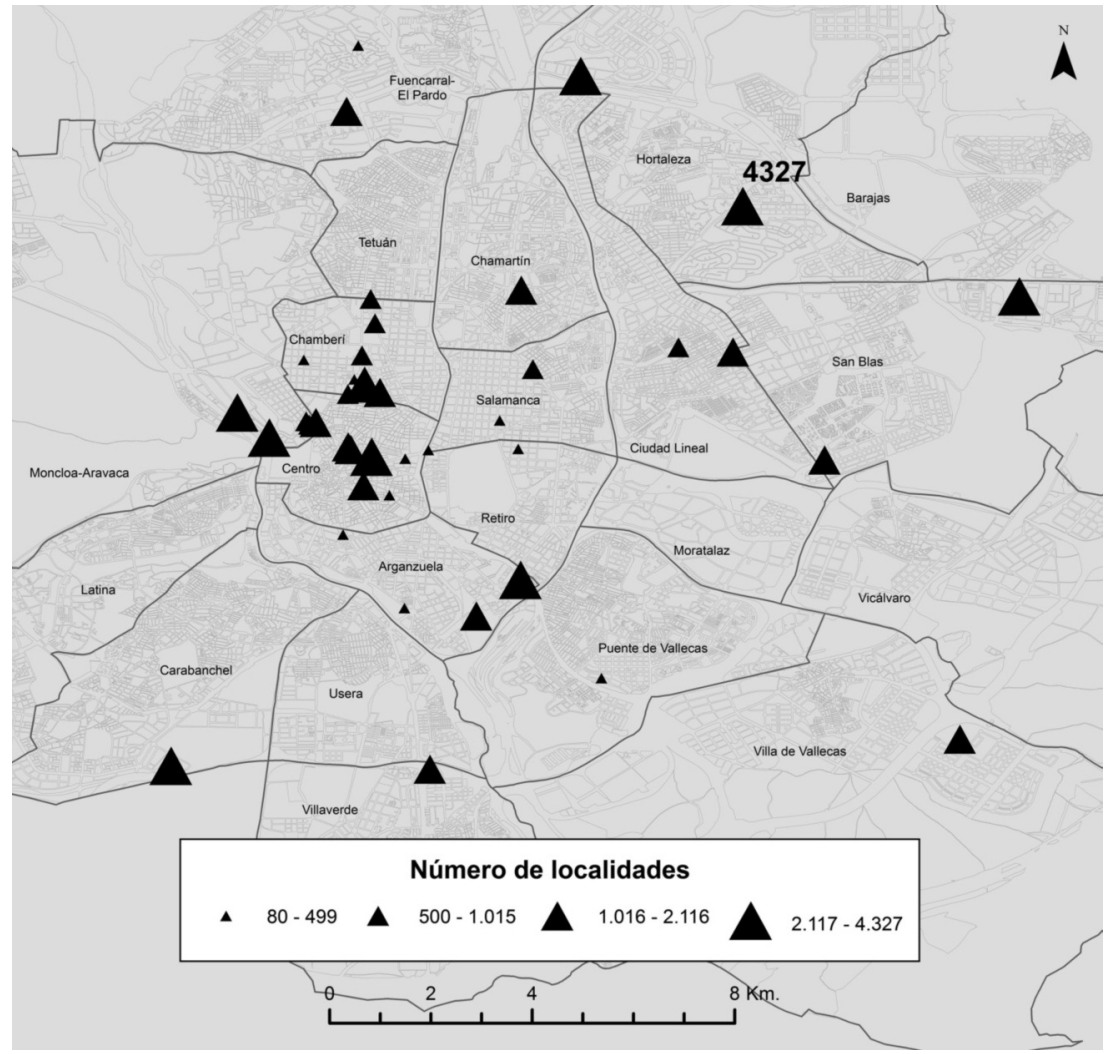

Fuente: AIMC (2013); y Dirección General del Catastro Madrid (2014). 
Los cines de verano y los cines de arte y ensayo y/o vinculados a la actividad de centros culturales aportan el 8\% y el 3\% del aforo madrileño. En los primeros, el cine del Parque de la Bombilla, con 3.000 localidades, es el mayor de su género, mientras que entre los segundos, con capacidades siempre por debajo de 500 espectadores, el cine Doré, de la Filmoteca Nacional, es el primero con 437 localidades. El grado de implantación del cine digital y 3D únicamente se constata en el cine Berlanga, de la calle Andrés Mellado (figura 11 y 12).

De «Los Miércoles al Cine» a la defensa del «Palacio de la Música»: DINÁMICAS DE LOS CINES MADRILEÑOS EN EL CONTEXTO DE CRISIS

A pesar de los esfuerzos puestos en marcha por los empresarios del sector de la exhibición para adecuar las salas de la ciudad a las características actuales de la demanda y por aportar nuevos valores a partir de su integración con otras formas de consumo, el cine no ha conseguido incrementar de manera generalizada su popularidad entre las formas de consumo de ocio de la población. Antes al contrario, nuevos factores como el auge de la "piratería» o el descenso de la demanda por efecto de la crisis económica, han acentuado en los últimos años la caída de la afluencia, hecho que se manifiesta de manera generalizada en el conjunto del país. Por otro lado, problemas internos como la elevada tributación que grava al negocio del cine y el descenso de las ayudas públicas al sector, han colocado a los empresarios del cine en una situación delicada para garantizar la viabilidad de sus negocios en el futuro (Días de Cine, 2014). Sus reiteradas demandas en los medios de comunicación por un mayor compromiso de las autoridades para la resolución de estas problemáticas y el apoyo prestado a sus requerimientos por diferentes agentes de la sociedad civil, han hecho del "problema del cine» una cuestión de plena actualidad con repercusiones en diferentes aspectos de la gobernabilidad de las ciudades y en cuestiones de interés general relacionadas con la gestión del patrimonio y de la actividad cultural. En este contexto, las soluciones ensayadas para mitigar los problemas que afectan al cine han tratado de fomentar una recuperación de la demanda poniendo en marcha estrategias diversas que pasan por el abaratamiento general de los precios, la articulación de su actividad con otras prácticas culturales y educativas o mediante la potenciación de sus valores como producto creativo y cultural. Todo ello introduce nuevos componentes y dinámicas en el espacio de exhibición madrileño, cuyas sinergias han afectado de uno u otro modo al conjunto de locales que lo conforman. 
La exitosa campaña de «Los Miércoles al Cine», puesta en marcha en España entre 2013 y 2014, han conseguido incrementar de manera generalizada la afluencia a las salas en los momentos de celebración de este evento, gracias a la reducción general del precio de la entrada. En el conjunto del país, los cines que se adhirieron a principios de 2014 fueron 359, de los que 45 estaban en la Comunidad de Madrid y 25 de ellos, en la capital (Guisado, 2014). La ampliación de los establecimientos participantes en las fechas posteriores y la continuidad en su celebración ha permitido «meter en los cines [españoles] a 3.251.558 espectadores» hasta el mes de abril («un 145\% más que durante los mismos miércoles que el año anterior»), lo que ha animado a los empresarios del sector a prolongar esta iniciativa hasta el verano. Por otro lado, este evento se ha visto apoyado por otros similares como la «La Fiesta del Cine» que se celebra desde 2009 y que en su última edición en abril de 2014 ha conseguido movilizar a 1.6 millones de personas en toda España (1.8 millones de entradas y un 15\% más que en 2013), a pesar de la coincidencia con otro fenómeno fundamental de nuestro entretenimiento de masas, la celebración de la Liga de Futbol (Casado, 2014b). Aunque en términos generales estas iniciativas no han tenido su contraparte en un incremento real de la recaudación (Casado, 2014a), su desarrollo ha permitido relanzar la afluencia en momentos puntuales y con ello quizás, sentar precedentes para garantizar una afluencia más sostenida en el futuro. Con esta finalidad, cadenas como los Renoir han ampliado los periodos de descuentos más allá de los momentos en los que tienen lugar estos eventos, y el «debate sobre la necesidad de rebajar los precios más allá de ofertas puntuales» se ha reabierto entre consumidores y empresarios (Guisado, 2014).

Así mismo, como refuerzo a estas iniciativas, los cines de la ciudad han introducido nuevas fórmulas para el consumo de esta actividad que tratan de incrementar el valor de la experiencia de asistir al cine y con ello ofrecer una alternativa atractiva frente a otras formas de ocio, principalmente las que se desarrollan en los hogares. La expansión de las nuevas tecnologías audiovisuales para la exhibición, la mejora de la confortabilidad en las salas y el fomento a la integración con otras formas de consumo vinculadas al comercio o al ocio, van en esta línea entre los cines de la región y los españoles (Álvarez y López, 2006). Del mismo modo, se ensayan con nuevas fórmulas de fidelización como los bonos descuentos, las sesiones temáticas, los pases conmemorativos en torno a sagas de filmes, etc., se han puesto en marcha alternativas novedosas en los servicios de atípicos e incluso se han incorporado «mesas de cena y sillas», servicios de cátering y camareros en las salas de algunos cines (Hernández, 2014). 
Por otro lado, los centros culturales y artísticos que funcionan en la ciudad han incorporado el cine como complemento a las actividades que ofrecen a sus usuarios a través de sesiones vinculadas a las temáticas de otros eventos celebrados en los centros o en el marco de ciclos monográficos, documentales o de autor (Sala Iberia, Sala del Círculo de Bellas Artes, etc.). Esta actividad apoya la que desarrollan los cines de arte y ensayo en torno a temáticas y enfoques similares en diferentes lugares del centro urbano y contribuye a reforzar la labor que desarrolla la Filmoteca Nacional a través del Cine Dore. En última instancia, todo ello constituye un reflejo del papel que está jugando el cine en el marco de las diferentes alternativas existentes en la ciudad para el consumo cultural y de manera general, de los vínculos que ha establecido esta actividad, como industria artística y creativa, con las demandas actuales en favor de la defensa y la puesta en valor del patrimonio en sus diferentes manifestaciones. En este sentido, la Recomendación de la UNESCO para la «Salvaguardia y Conservación de las Imágenes en Movimiento» (UNESCO, 1980) marcó un punto de partida hacia la protección del patrimonio filmográfico que ha llevado en la actualidad a propuestas concretas que aspiran a conseguir la declaración del cine analógico como «Patrimonio Universal de la Humanidad» (en el contexto de tránsito hacia el cine digital) (EFE, 2013), y a iniciativas para su divulgación, como la de «La Filmoteca Española On Line» de RTVE, que ha acercado a la población las producciones del NO.DO. y de otras piezas audiovisuales a través de la web (RTVE, 2012). Todo ello tiene su reflejo en muchas de las actividades que se desarrollan en los cines ubicados en centros culturales, ha impulsado la actualización o apertura de cines como el Berlanga (antiguo cine California, en la calle Andrés Mellado) y el del Centro Cultural Paco Rabal, y forma parte de la oferta de los cines de arte y ensayo, que como el Pequeño Cine Estudio «ofrece la oportunidad de visionar en pantalla grande, títulos clásicos pertenecientes [...] a la época en la que el cine se escribía en blanco y negro» (Pequeño Cine Estudio, s/f).

Así mismo, los cierres y las transformaciones de cines, muchos de ellos históricos y dotados de una destacada singularidad arquitectónica, han tenido lugar de forma paralela a un incremento de la sensibilidad por la conservación y el mantenimiento del patrimonio y el paisaje de la ciudad, lo que ha contribuido a aportar a las demandas de los particulares y colectivos preocupados por la pérdida generalizada de cines en Madrid nuevas reivindicaciones para lograr un mayor compromiso en la protección de los locales históricos. En este contexto, el colectivo Salvemos los Cines..., integrado en la asociación Madrid Ciudadanía y Patrimonio, desarrolla un importante labor de divulgación y de concienciación entre los medios de comunicación para evitar la pér- 
dida de locales emblemáticos del cine en Madrid bajo reformas de los inmuebles para albergar nuevas funciones que pueden desvirtuar su imagen y fisionomía original.

Las reivindicaciones de este colectivo se desarrollaron inicialmente en los cines cerrados y reconvertidos del eje del Gran Vía, especialmente tras las previsiones de que el Palacio de la Música fuera convertido en una tienda de ropa. Este cine, tras su cierre en 2008, fue adquirido por el Grupo Caja Madrid que intentó sacar adelante un proyecto de transformación del mismo en auditorio (Sánchez Fernández, 2013; EUROPA PRESS, 2014), animado en parte por el éxito que estaban teniendo en la Gran Vía los espectáculos musicales tipo «Broadway».

FIGURA 13

\section{LOCALES HISTÓRICOS DEL CINE EN MADRID}

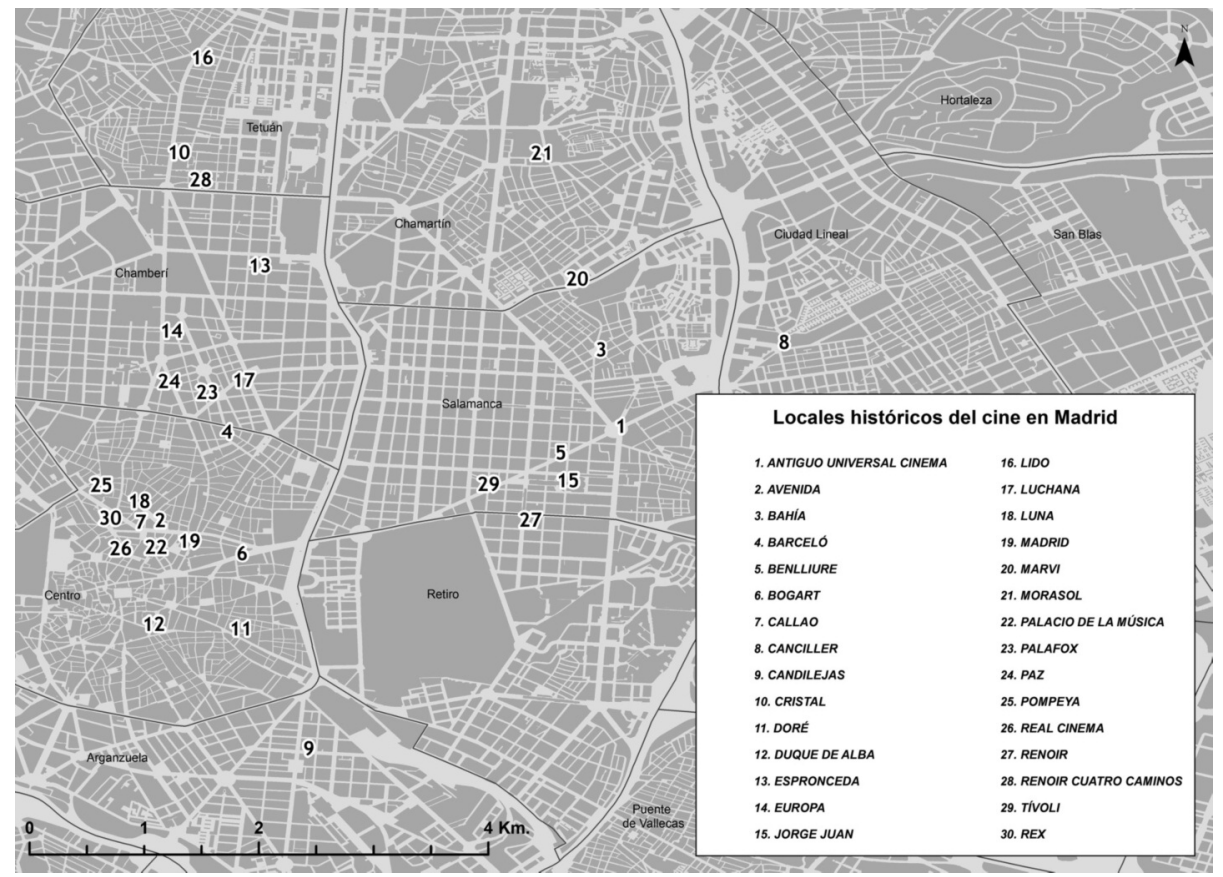

Nota: este mapa recoge los locales de cines -en uso, cerrados o transformados- singularizados por su interés arquitectónico en la Guía de Arquitectura COAM (Berlinches, 2003) y los contemplados en el Plan de Protección de Cines Históricos presentado por el colectivo Salvemos los Cines y Teatros de Madrid (Madrid Ciudadanía y Patrimonio, 2014).

Fuente: fuentes señaladas y Dirección General del Catastro Madrid, 2014. 
Sin embargo, en 2012 el proyecto se paralizó y comenzó a barajarse la posibilidad de aprovechamiento del inmueble para otros usos. La opción de reforma para convertirse en una tienda de ropa tiene un ejemplo cercano en el cine Avenida que actualmente funciona bajo este uso (EUROPA PRESS, 2014). Su reconversión no estuvo ajena de críticas (Sánchez Fernández, 2013), hecho que marcará un precedente para las reivindicaciones actuales con el Palacio de la Música, y han permitido a su vez, extenderlas hacia salas históricas situadas en otros distritos, lo que da cuenta de la importancia que adquieren estos edificios en el conjunto de la ciudad (Madrid Ciudadanía y Patrimonio, 2014; y Días de Cine, 2014) (figura 13).

\section{CONCLUSIÓN}

A pesar de que las autoridades aún no han tomado una postura decidida sobre esta cuestión, el contexto actual ofrece algunas posibilidades de interés que podrían ser exploradas para garantizar la preservación de los locales históricos del cine, así como para fomentar un mayor dinamismo de la actividad en el conjunto de la ciudad. El "Plan Madrid Centro" (Ayuntamiento de Madrid, 2011), destinado a fomentar la revitalización funcional de los distritos comprendidos dentro del anillo de la M-30, ofrece expectativas en este sentido al abordar la planificación de este espacio bajo un prisma novedoso que pretende hacer de ellos un área integrada a las dinámicas del conjunto de la ciudad mediante la potenciación de los valores que le confiere su posición centralizada y el dinamismo cultural e innovador de las actividades que se desarrollan en su seno.

En este marco, aunque la evolución reciente del negocio del cine está condicionada por la caída generalizada que viene afectando a la afluencia a las salas desde las últimas décadas, las actuaciones enfocadas a fomentar la asistencia en el marco de las ofertas del «Los Miércoles al Cine»y «La Fiesta del Cine» han demostrado las posibilidades que aún conserva esta forma de diversión para continuar movilizando a la población. Los objetivos del Plan Centro abren la posibilidad de lograr un mayor aprovechamiento de estas sinergias a través de una planificación integral enfocada a fomentar una mayor articulación de la actividad del cine con las dinámicas de estos espacios, hecho que en última instancia permitiría reforzar las que desarrollan las empresas, instituciones y agentes diversos que conforman el clúster de la economía del conocimiento que se concentra de forma mayoritaria en este espacio (Sánchez Moral, 2013) ${ }^{12}$.

12 Servicios Avanzados a Empresas, Servicios Intensivos de Conocimiento e Industrias Culturales. 
Por otro lado, existe un contexto favorable a la protección de los bienes de patrimonio que conserva la localidad, una legislación específica para estos fines y un plan macro de protección de paisaje que aunque carece de carácter normativo anima a preservar los escenarios singulares de la ciudad y de los elementos que los conforman y los conformaron. La presencia siempre destacada del cine en los diferentes distritos de la villa a lo largo del tiempo ha legado edificaciones, lugares y una memoria colectiva sobre la presencia de esta actividad en los espacios centrales y de la vida cotidiana en los barrios residenciales, susceptible de ser potenciada en este contexto y valorizada a partir de su integración con nuevas formas de ocio y de consumo cultural. La diversidad de facetas bajo las cuales se desarrollan ambas actividades en la actualidad y la importancia que tienen en nuestras formas de vida, ofrece la posibilidad de experimentar con nuevas alternativas que permitan recuperar la presencia de esta actividad en el marco de proyectos terapéuticos, culturales o de diversión destinados a reforzar cuestiones de interés general en el gobierno de la ciudad como la gestión de la educación o de los asuntos sociales, entre otros. Los esfuerzos realizados por los empresarios del cine para adecuar la actividad a las preferencias de la demanda actual y los nuevos formatos que prosperan en los centros culturales, dan cuenta de la disponibilidad del sector para avanzar hacia nuevas fórmulas para fidelizar a los espectadores, conservar los negocios y estimular la asistencia al cine como habito de ocio entre los madrileños. Bajo formatos más flexibles, los colegios, los centros de mayores, las instalaciones municipales, las ludotecas y por supuesto, los antiguos locales de cine del centro y de los barrios, podrían convertirse en los continuadores de una práctica de ocio que contribuyó a dotar de una mayor cohesión social a la ciudad, a extender la educación a través de los filmes y difundir nuevas modas y costumbres entre la población. Todo ello permitiría recuperar espacios heredados del cine al tiempo que se reforzaría la afluencia a los que actualmente están en funcionamiento.

Finalmente, la experiencia reciente de incremento de la afluencia en «La fiesta del cine» o «Los Miércoles al cine», invitan a buscar paralelos con experiencias anteriores en las que el cine tuvo un protagonismo relevante para dinamizar los paisajes de la ciudad, como fue la celebración de la capitalidad cultural en 1992. En este evento, cines, asociaciones, teatros, colegios y museos, entre otros, fueron coordinados por el consistorio para animar y dar a conocer la riqueza del patrimonio, de la historia y de los paisajes de la ciudad, hechos que supusieron a la vez que un revulsivo para la imagen de Madrid en el exterior, una declaración explicita de los responsables municipales en la revisión del Plan General de Ordenación Urbana de Madrid por continuar apro- 
vechando en un futuro las sinergias de «de las actividades culturales [...] por su fuerte incidencia en la vida económica de la ciudad» (García Ballesteros, 1992).

Al igual que entonces, el contexto actual, previo a la aprobación definitiva del Plan General de Ordenación Urbana de Madrid y favorable a potenciar el desarrollo de nuevas formas de producción en el marco de la economía creativa y del conocimiento tras la crisis inmobiliaria (Barrado, 2013; Sánchez Moral, 2013), ofrece un marco idóneo para buscar alternativas para garantizar la conservación de los locales históricos del cine que se muestren en sintonía con preocupaciones generales vinculados a la conservación del patrimonio y del paisaje, y el mantenimiento de la imagen de la ciudad en el exterior. De este modo, actuaciones anteriores de gran interés como el plan de recuperación de los «Itinerarios de Cines y de Teatros» se verían reforzadas por una estrategia de revitalización de carácter general, en un contexto social favorable a la intervención pública para promocionar y proteger el patrimonio y por la persistencia de una corriente turística de entidad, cuyas principales motivaciones para acudir a Madrid son disfrutar de sus atractivos culturales (Castaño Blanco et al., 2003) y de sus paisajes urbanos, entre ellos los que contribuyeron y contribuyen a crear los cines.

\section{BIBLIOGRAFÍA}

AIMC: Asociación para la Investigación de Medios de Comunicación, (2013): Censo de cines 2013, Madrid, AIMC, 403 pp., http://web.discine.es/APP/pdf/cines13.pdf (Fecha de consulta: 20/6/2015).

Almax (1991): Atlas de Madrid y Periferia, Madrid, Mateu Cromo S.A., 288 pp.

Álvarez Monzoncillo, José María (1993): "3. La exhibición cinematográfica”, en José María Álvarez Monzoncillo (dir. y coord.), La industria cinematográfica en España (1980-1991), Madrid, Fundesco-Ministerio de Cultura.

Álvarez Monzonillo, José María (2004): "El entretenimiento que viene", El País, 5 de septiembre de 2004, http://elpais.com/diario/2004/09/05/negocio/1094390069_ 850215.html (Fecha de consulta: 5/4/2016).

Álvarez Monzonillo, José María y López Villanueva, Javier (2006): La situación cinematográfica española: políticas públicas ante los mercados digitales. Documento de trabajo 92/2006, Madrid, Fundación Alternativas, 52 pp.

Ayuntamiento de Madrid (2011): Proyecto Madrid Centro, Madrid, Área de Gobierno, Urbanismo y Vivienda, http://www.madrid.es/portales/munimadrid/es/Inicio/ Ayuntamiento/Urbanismo-e-Infraestructuras/Proyecto-Madrid-Centro?vgnextfmt=default\&vgnextoid=0b65488f7c742310VgnVCM1000000b205a0aRCRD \&vgnextchannel=8dba171c30036010VgnVCM100000dc0ca8c0RCRD (Fecha de 
consulta: 3/5/2014).

Báez y Pérez de Tudela, José María (2012): Fútbol, cine y democracia. Ocio de masas en Madrid 1923-1936, Madrid, Alianza Editorial, 351 pp.

Barrado Timón, Diego (2013): "Cultura urbana e industrias culturales como alternativa al modelo económico heredado: experiencias españolas recientes en las ciudades de Sevilla y Cáceres", en Manuel Valenzuela Rubio (coord.), Las ciudades españolas en la encrucijada. Entre el 'boom' inmobiliario y la crisis económica, Madrid, Real Sociedad Geográfica, con la colaboración de la Asociación de Geógrafos Españoles, pp. 411-453.

Berlinches Acín, Amparo (dir.) (2003): Arquitectura de Madrid, Madrid, COAM, 4 vols. Bosque Maurel, Joaquín (2000-2001): "Desarrollo urbano y estilos arquitectónicos: la Gran Vía de Madrid", Boletín de la Real Sociedad Geográfica, CXXXVII-CXXXVIII, pp. 61-87.

Casado, D. (2014a): "Los cines hacen cuentas para estudiar si alargan los miércoles con entradas a 3.90 euros", Hoycinema.abc, 2 de abril de 2014, http://hoycinema. abc.es/noticias/20140402/abci-fiesta-cine-miercoles-promocion-201404011526. html (Fecha de consulta: 3/5/2014).

Casado, D. (2014b): "Los Miércoles al Cine con entradas a 3.90 euros se extiende hasta el mes de julio", Hoycinema.abc, 3 de abril de 2014, http://hoycinema.abc. es/noticias/20140403/abci-fiesta-cine-espectadores-subida-201404031140.html (Fecha de consulta: 3/5/2014).

Castaño Blanco, José Manuel, Moreno Sáez, Alfredo, García Dauder, Silvia y Crego Díaz, Antonio (2003): "Aproximación psicosocial a la motivación turística: variables implicadas en la elección de Madrid como destino", Estudios Turísticos, 158, pp. 5-41.

Crespo Jordán, María Mercedes (1974a): "Estudio geográfico de la distribución espacial de las salas de cine madrileñas", Geographica, 16, 1/4, pp. 73-131.

Crespo Jordán, María Mercedes (1974b): "Un aspecto del análisis geográfico del centro de negocios madrileño: localización y caracteres de los locales de espectáculos", memoria de licenciatura, director: D. José Manuel Casas Torres, Facultad de Filosofía y Letras, Universidad Complutense de Madrid.

CSIC, HISDI-MAD: Ide Histórica de la Ciudad de Madrid, Unidad de SIG - CCHS, http://www.idehistoricamadrid.org/hisdimad/index.htm (Fecha de consulta: 3/5/2012).

Cuenca Cabeza, Manuel (2000): "III. Manifestaciones del ocio en la sociedad actual", en Manuel Cuenca Cabeza, Ocio humanista. Dimensiones y manifestaciones actuales del ocio, Bilbao, Universidad de Deusto, pp. 187-278.

Días de Cine (2014), Gerardo Sánchez (dir.), RTVE, 4 de abril de 2014, "El cine en los cines", http://www.rtve.es/alacarta/videos/dias-de-cine/cine-cines/2487927/\#aHR0 cDovL3d3dy5ydHZlLmVzL2FsYWNhcnRhL2ludGVybm8vY29udGVudHRhYmxlLnNodG1sP3BicT0zJmlvbnRoRmlsdGVyPTQmb3JkZXJDcml0ZXJ pYT1ERVNDJmlvZGw9VE9DJnllYXJGaWx0ZXI9MjAxNCZsb2NhbGU9ZXMmc GFnZVNpemU9MTUmY3R4PTIwMjEwJmFkdlNlYXJjaE9wZW49ZmFsc2U= (Fecha de consulta: 3/5/2014). 
Dirección General del Catastro Madrid (2014): "Cartografía Catastral Urbana Digital", http://www.catastro.meh.es/esp/productos.asp\#tabla_productos (Fecha de descarga: 19/03/2014).

EFE (2013): "El cine... ¿Patrimonio de la humanidad?", hoycinema.abc, 22/4/2014. http://www.hoycinema.com/actualidad/noticias/cine-patrimonio-humanidad20130422-608006.html (Fecha de consulta: 3/5/2014).

EFE (2014): "La taquilla española en 2013, crónica de un desplome anunciado", Cinco Días, 4/1/2014, http://cincodias.com/cincodias/2014/01/04/empresas/ 1388838461 _934401.html (Fecha de consulta: 21/7/2014).

EUROPA PRESS (2014): "Vuelven los descuentos a los cines de la región", El Mundo, 31 de enero de 2014, http://www.elmundo.es/madrid/2014/01/31/52ebb38422601 d6b718b4577.html (Fecha de consulta: 21/7/2014).

Ferrer Regales, Manuel (2003): "I. II. Centro y periferia”, en Manuel Ferrer Regales: Los centros históricos en España, teoría, estructura y cambio, Pamplona, Gobierno de Navarra, pp. 47-66.

Gámir Orueta, Agustín (2001): "Del cine unipantalla al Megaplex. Transformaciones recientes en la industria de la exhibición cinematográfica en España", Anales de Geografía de la Universidad Complutense, 21, pp. 223-253.

García Ballesteros, Aurora (1993): "El espacio cultural de «Madrid 1992»", Estudios Geográficos, 54/202, pp. 521-536.

García Escalona, Emilia (2000): "Cambios en las formas y lugares de consumo en Madrid”, Estudios Geográficos, 61/238, pp. 73-102.

González Torreblanca, Nieves (2007): Madrid. Patio de butacas, Madrid, La Librería, $128 \mathrm{pp}$.

Gran Vía, Memoria de Madrid (1933): "Cine Actualidades. Noticias, septiembre de 1933", Revista Cortijos y Rascacielos, otoño, 5 pp., ttp://granvia.memoriademadrid. es/fondos/OTROS/Imp_21289_hem_coryras_1933otonol4actualidades.pdf (Fecha de consulta: 5/4/2016).

Guisado, P. (2014): "Vuelven los descuentos a los cines de la región", El Mundo, 16 de enero de 2014, http://www.elmundo.es/madrid/2014/01/16/52d725bfca4741d9238 b458c.html (Fecha de consulta: 3/5/2014).

Hernández, Luna (2014): "Cine, jamón y copa de vino", La Razón, 25 de enero de 2014, http://www.larazon.es/detalle_normal/noticias/5240725/cine-jamon-y-copade-vino\#.U2TWxfl_uSo (Fecha de consulta: 3/5/2014).

Herraez, Sigfrido (2000): "La rehabilitación del centro histórico de Madrid", Informes de la Construcción, 51/465, pp. 41-46.

INE: Instituto Nacional de Estadística (2003): La Sociedad Española tras 25 años de Constitución, Madrid, INE, 243 pp.

INE: Instituto Nacional de Estadística (2008): "El ocio en cifras", Cifras INE, 4/2008, 8 pp.

ICAA-MCU: Instituto de la Cinematografía y de las Artes Audiovisuales del Ministerio de Cultura, (2003): Evolución del cine español, 1996-2003, Madrid, Ministerio de Cultura, Instituto de la Cinematografía y de las Artes Audiovisuales, 33 pp., 
http://www.mecd.gob.es/cultura-mecd/en/dms/mecd/cultura-mecd/areascultura/cine/informacion-servicios/in/informes-publicaciones/EvolucCineEsp1996-2003.pdf (Fecha de consulta: 15/05/2013).

Jiménez Hernández, Miguel (2000-2001): Madrid. Guía de calles, Madrid, Océano Grupo Editorial, 236 pp.

López García, Victoriano (1945): La industria cinematográfica española, Madrid, Asociación Nacional de Ingenieros Industriales.

López Martín, Laura (2009): "Aproximación a los oficios de cine en España (desde sus inicios hasta 1936)", Espacio, Tiempo y Forma, Serie V, Historia Contemporánea, 21, pp. 77-100.

Luis Gómez, Alberto (1988): "Capítulo 2. Ocio, tiempo libre, turismo y recreación. Algunos problemas conceptuales", en Alberto Luis Gómez (1988), Aproximación histórica al estudio de la geografía del turismo. Guía introductoria, Barcelona, Anthropos, pp. 29-59.

Madrid Ciudadanía y Patrimonio (2014): ACTA REUNIÓN: Salvemos los cines, 3 Abril, http://madridciudadaniaypatrimonio.org/node/537 (Fecha de consulta: 3/5/2014).

Ministerio de Educación Cultura y Deportes (1992-1995/2005-2012): Estadísticas de Cinematografía, Madrid, MECD.

OMT: Organización Mundial del Turismo (2012): "La OMT da la bienvenida al turista mil millones", PR No.: PR12077, 13 de diciembre de 2012, http://media.unwto. org/es/press-release/2012-12-13/la-omt-da-la-bienvenida-al-turista-mil-millones (Fecha de consulta: 3/5/2014).

Pequeño Cine Estudio (s. f.): Historia, http://www.pcineestudio.es/ (Fecha de consulta: 3/5/2014).

Ponce Herrero, Gabino y Espinosa Seguí, Ana (2013): "La recuperación urbana y comercial de las ciudades alicantinas", en Manuel Valenzuela Rubio (coord.), Las ciudades españolas en la encrucijada: Entre el 'boom' inmobiliario y la crisis económica, Madrid, Real Sociedad Geográfica, con la colaboración de la Asociación de Geógrafos Españoles, pp. 389-411.

Prieto Flores, María Eugenia (2003): "Actividades de ocio y renta en la Comunidad Autónoma de Madrid. Aproximación a la lógica espacial de las salas de exhibición cinematográfica", en Antonio Moreno (dir.), La distribución espacial de la renta en la Comunidad de Madrid, Madrid, Comunidad de Madrid, pp. 129-152.

Quirós Linares, Francisco (2009): Las ciudades españolas en el siglo XIX, Madrid, Trea, $430 \mathrm{pp}$.

Rodríguez Rodríguez, Vicente (dir.) (2004): "III. Cambios demográficos en el Distrito Centro en la década de los 90", en Vicente Rodríguez Rodríguez (dir.), Cambios demográficos y transformaciones sociales en el centro urbano de Madrid, Madrid, Comunidad de Madrid, pp. 63-148.

RTVE (2012): "RTVE y Filmoteca Española lanzan en Internet el mayor fondo histórico audiovisual de España", rtve.es, 20 de diciembre de 2012, http://www.rtve.es/ noticias/20121220/archivo-filmoteca-no-do-mayor-fondo-historico-audiovisual/590521.shtml (Fecha de consulta: 3/5/2014). 
Ruiz Palomeque, Eulalia, Pozo Rivera, Enrique y Lázaro y Torres, María Luisa de (2000): "Nuevas formas de comercio y consumo en Madrid: las grandes superficies", Estudios Geográficos, 61/238, pp. 125-144.

Sánchez Fernández, Miguel David (2013): Los cines de Madrid, Madrid, La Librería, $335 \mathrm{pp}$.

Sánchez Moral, Simón (2013): "Discutiendo alternativas de desarrollo para la ciudad de Madrid en el horizonte Europa 2020: Retos y amenazas desde la perspectiva de los trabajadores del conocimiento", Anales de Geografía de la Universidad Complutense de Madrid, 33/2, pp. 155-177.

UNESCO (1980): Actas de la Conferencia General. 21.a reunión. Belgrado. 23 de septiembre - 28 de octubre de 1980. Vol. 1. Resoluciones, Vendôme, UNESCO, 178 pp., http://unesdoc.unesco.org/images/0011/001140/114029S.pdf (Fecha de consulta: 3/5/2014).

Vidal Domínguez, María Jesús y Fernández Portela, Julio (2012): "Crecimiento metropolitano y nuevas tipologías residenciales en la ciudad de Madrid (España)", en Comité Español de la UGI (ed.), Contribución Española al $32^{\circ}$ Congreso de Colonia 2013. Comité Español de la Unión Geográfica Internacional, Madrid, AGE, CSIC, Real Sociedad Geográfica, Instituto Geográfico Nacional y Ministerio de Fomento, pp. 300-313.

WRLA: World Leisure And Recreation Association (1994): "Carta Internacional para la Educación del Ocio”, traducción de Yolanda Lázaro Fernández, ELRA (European Liuse and Recreation Asociaciation), Summer 1994, pp. 13-16.

Zapata (1928): "El cine Callao", Revista Estampa, 3 de abril de 1928, http://www.me moriademadrid.es/buscador.php?accion=VerFicha\&id=21997\&num_id=3\&num_ total=5 (Fecha de consulta: 5/4/2016).

Zárate Martín, Manuel Antonio (2012): Geografía Urbana. Dinámicas locales y procesos globales, Madrid, UNED, $352 \mathrm{pp}$.

Zárate Martín, Manuel Antonio (2003): "Madrid, un modelo suprametropolitano de urbanización", Anales de Geografía de la Universidad Complutense, 23, pp. 283-304.

Fecha de recepción: 8 de agosto de 2014.

Fecha de aceptación: 24 de junio de 2015.

\section{RESUMEN}

Desde la aparición de los primeros cinematógrafos, hasta la inauguración de las grandes salas en los modernos centros comerciales, la frecuentación al cine en la ciudad de Madrid ha corrido en paralelo a los cambios que han afectado a su demanda en el marco de diferentes contextos sociales y culturales. En este trabajo se analizan los cambios que ha provocado este hecho en la conformación del espacio de exhibición cinematográfico madrileño a lo largo del tiempo y en las últimas décadas, fase en la que su desarrollo ha estado condicionado por los cierres de locales, el desarrollo de 
nuevas fórmulas de negocio que han alterado las características del cine convencional y la distribución territorial del aforo, y la emergencia de nuevas demandas para garantizar la conservación de los locales históricos del cine por sus valores patrimoniales.

Palabras Clave: ocio; cine; paisaje urbano; patrimonio.

\begin{abstract}
From the appearance of the first filmmakers to the opening of the large multiscreen cinemas in modern shopping malls, cinema attendance in the city of Madrid has run parallel to the changes that have affected its demand within different social and cultural contexts. This paper discusses the changes caused by this fact in shaping the film exhibition space in Madrid over time and in recent decades, a phase in which its development has been influenced by the closure of cinemas, the development of new business formulas that have altered the characteristics of conventional cinemas and the distribution of the audience, and the emergence of new demands to ensure the preservation of historical cinemas for their heritage value.
\end{abstract}

KEY WORDS: Leisure; cinema; cityscape; heritage. 